\title{
Agent discretion, regulatory policymaking, and different institutional arrangements
}

\author{
BERNARD STEUNENBERG \\ University of Twente, Faculty of Public Administration and Public Policy, 7500 AE \\ Enschede, The Netherlands
}

Accepted 24 July 1995

\begin{abstract}
This paper examines agent discretion that is a result of the structure of the legislative process. Based on several distributions of lawmaking powers, different games are analyzed in which players decide on regulatory policies. The analysis shows that agent discretion increases as lawmaking powers are differentiated and assigned to specialized players. Particularly, monopoly initiation power, which allows a player to act as a gatekeeper, has a substantial impact on discretion. Agent discretion will be even larger when these players also have heterogenous preferences. The framework that is developed in this paper permits comparisons across different political systems with regard to agent discretion and legislative control on policymaking.
\end{abstract}

\section{Introduction}

In the modern regulatory state, the legislature frequently delegates the authority to set regulatory policy to an agent, such as an agency, a minister in cabinet governments, local government, or any other official body. The relationship between the legislature and these agents has been the subject of much debate. The "political control" literature argues that in the U.S. the Congress is able to control regulatory agencies. In this view, Congress may induce agent compliance by using tools such as decentralized information gathering, ex post sanctions and political appointments (Weingast and Moran, 1983; Weingast, 1984), carefully designed administrative procedures (McCubbins, 1986; McCubbins, Noll, and Weingast, 1987, 1989; Macey, 1992), and court review (Ferejohn and Weingast, 1992). Consequently, the introduction of new regulatory policies is not a result of a shift of agency preferences; rather, it is caused by changes in the preferences of the dominant legislative coalition

\footnotetext{
* I thank Patrick Dunleavy, Martin van Hees, Manfred Holler, Mary Olson, an anonymous referee, and participants at seminars at the University of Twente, the Netherlands, the University of Hamburg, Germany, the London School of Economics and Political Science, the 1994 Public Choice Society Meeting in Austin, Texas, and the 1994 Summerschool of the Netherlands Institute of Government, for helpful comments and suggestions.
} 
in Congress. Agent discretion may only result when information about agent performance is poor and costly to collect or when the legislature is not willing to oversee agent decision making (Calvert, McCubbins, and Weingast, 1989). With its focus on agent behavior, this literature does not pay sufficient attention to decision making within the legislature. It passes over difficulties the legislature may have in deciding collectively on its actions. Some models of administrative behavior do focus on this problem and show that, even when the legislature knows that an agent has deviated from its policy preferences, it may not be able to do much about it. The legislative process can be hampered by majority rule cycles, which the agent may employ to its advantage (Hill, 1985). Furthermore, new legislation can be blocked if political actors do not agree on any deviation from the current agent policy (Ferejohn and Shipan, 1990; Eskridge and Ferejohn, 1992). In these cases, it is neither a lack of information nor the unwillingness of the legislature to review agent decisions, but the inability to reach legislative agreement that provides the agent with the opportunity to select a policy that is closer to its ideal point.

The purpose of this paper is to analyze the extent to which agent discretion is affected by different institutional arrangements that determine the structure of the legislative process. At least two reasons exist for focusing on these structural characteristics. First, as Shepsle (1979) and Ostrom (1986) indicate, institutional arrangements are as important as preferences in determining the outcome of decision making. Since institutional arrangements codetermine the feasibility of legislative action to change agent policies, they also affect the extent to which an agent is able to deviate from the policy that is preferred by the legislature. Second, the structure of the legislative process can be changed by the legislature itself. If specific characteristics of this process affect agent policymaking, a reform of these procedures may increase legislative control and lead to different regulatory policies. It is therefore of importance to show how different institutional arrangements affect the outcomes of these processes.

The characterization of agent discretion in this paper differs from the literature that explores bureaucratic discretion based on informational or expertise advantages (Niskanen, 1971; Breton and Wintrobe, 1975; Miller and Moe, 1983), or uncertainty about agent preferences (Calvert, McCubbins, and Weingast, 1989). In this literature, discretion is a result of information asymmetry in favor of the agent. It can be reduced by changing the incentives to the agent (Bendor, Taylor, and Van Gaalen, 1985, 1987) or reducing the costs of information to the legislature about agent performance or the effects of different policy instruments (Banks, 1989; Banks and Weingast, 1992). In this paper discretion is not based on information but on the structure of the legislative process. This does not imply that information is not regarded as 
an important source of discretion. The point is that the agent has an additional opportunity to deviate from the policies preferred by the legislature. So information-induced discretion needs to be distinguished from the structureinduced discretion, and the latter is analyzed in this paper. Consequently, policymaking will be analyzed in an environment of complete and perfect information, which precludes the interference between these two different forms of discretion.

The delegation of policymaking power to an agent changes the decision making process significantly. Since the agent is now allowed to set the new policy, the legislature may only change this policy when it is able to force the agent to change its position by enacting new legislation. In this process, the legislature has to take the agent's policy choice as the point from which it may propose a change. This characteristic provides the agent an important "first mover" advantage, as Ferejohn and Shipan (1990) have noted. By changing the status quo ex ante to a status quo ex post, which forms the starting point for legislative action, the agent is able to induce its preference on the final outcome. Examples of agents that may employ this opportunity include cabinet ministers in parliamentary systems, who may set standards in fields such as competition policies, working conditions and safety regulation, and environmental protection, "independent" central banks with powers in the field of monetary policy, and U.S. agencies such as the Environmental Protection Agency and the Federal Trade Commission. In the European Union, the Commission also has this strategic advantage when the Council delegates the Commission the power to set policies which are only subject to the consultation of other bodies and possibly Council review by qualified majority (see Kapteyn and VerLoren van Themaat, 1990: 240-247).

Policymaking that follows this line differs from models in which a clear and exogenous status quo ex ante exists, which can only be changed by explicit legislative approval (see, for instance, Romer and Rosenthal, 1978, 1979; Weingast and Moran, 1983; Kiewiet and McCubbins, 1988; Matthews, 1989). These models focus on statutory decision making and describe processes in which the status quo as embedded in the current statute has to be replaced by a new statute in order to allow for change. A well-known example of this is budgetary decision making, which typically requires the legislative approval of the new budget before the executive is allowed to spend more than the status quo ex ante or reversion level. In these processes, the agent may suggest some alternative for legislative consideration, but ultimately the legislature has to accept a new proposal in comparison to the status quo ex ante.

In recent contributions to the theory of administrative behavior, the role of the judiciary in policymaking is also taken into account (Spiller and Gely, 1992; Ferejohn and Shipan, 1990; Spiller and Spitzer, 1992; Ferejohn and 
Weingast, 1992). Eskridge and Ferejohn (1992), for instance, take the view that courts are permitted to reinterpret a statute to any point along a policy dimension. As a consequence, their model predicts that agencies do not have any discretion and are induced to follow court preferences in formulating public policies. ${ }^{1}$ However, in most of the other models the courts may play a much more modest role in the policymaking process than Eskridge and Ferejohn suggest. In this paper I assume that court review is primarily concerned with the question of whether or not an agent is authorized to set regulation, that is, to make a decision with respect to some "domain" or policy space. If the agent is allowed to set a policy along a policy dimension X, as I will assume, the policy itself is no longer subjected to court review and can only be reversed by the legislature. Therefore, I will not explicitly model court review in this paper, setting out instead from a policy dimension the agent is authorized to use.

The analysis demonstrates that the structure of the legislative process may allow for substantial agent discretion. Discretion is approached as a set of potential policies than can be selected by the agent without triggering legislation. It is not a distance between the agent's actual choice and some normatively attractive point, such as the preference of the median voter, or the initial policy agreement within the legislature (Calvert, McCubbins, and Weingast, 1989). In this way discretion is distinguished from agent preferences. So the legislature may affect discretion as well as agent preferences to increase its control on regulatory policymaking. The fact that legislative agreement is not always possible provides the agent with various strategic options in the policymaking process and forms the basis of the equilibrium policies identified in this paper. As the agent is allowed to make the first move, it will select its best policy such that the players in the legislature cannot pass a bill that will change this choice. The equilibrium has two important properties. First, the agent is the only active participant. The agent selects a policy that will be accepted by the player with initiation power. It therefore does not introduce a new bill, so in equilibrium no legislative action will be observed. Second, the public policy that will be implemented in equilibrium is not only a result of the preferences of the agent, but also the preferences of the players with legislative power. The agent anticipates all future courses of action and chooses a policy that will not be reversed in a subsequent stage of the game.

The paper is organized as follows. Section 2 introduces a model for the analysis of regulatory policymaking, based on the methodology of positive political theory (see, for instance, Ordeshook, 1992). In Section 3, I derive some general results for what I call policy games. These games consist of different sets of institutional arrangements that define the sequence of play and 
the actions available to players. The games analyzed in this paper are labeled as: (1) a veto game; (2) an override game; (3) a gatekeeping game; (4) a gatekeeping-veto game; and, (5) a gatekeeping-override game. In Section 4, I compare the effects of different arrangements on agent discretion and present some additional ways to control agent policymaking. In Section 5, I present the main conclusions of the paper.

\section{General framework}

To analyze agent discretion and the extent to which the legislature controls regulatory decision making, a model will be used with three types of players: (1) $l$ members of a legislature, $\mathrm{L}=\{1,2, \ldots, l\}, \mathrm{L} \subseteq \mathrm{M} \subset \mathrm{N}$, with $\mathrm{N}$ as the set of players, (2) an executive $m \in \mathrm{N}, \mathrm{L} \cup\{m\}=\mathrm{M}$, and (3) an agent $a \in \mathrm{N}$, and $a \notin \mathrm{M}$. These players are assumed to decide on some regulatory issue which can be represented by a one-dimensional outcome space $X=\mathbb{R}$. The preference of a player $i$ over $\mathrm{X}$ is represented by a function $\mathrm{U}_{i}=\mathrm{U}_{i}(\mathrm{x})$. This function defines single-peaked preferences that satisfy the single-crossing property $\mathrm{dU}_{i} / \mathrm{dx}<\mathrm{dU}_{i} / \mathrm{dx}$ for $\forall \mathrm{x} \in \mathrm{X}, \mathrm{x}_{i}{ }^{*}<\mathrm{x}_{j}{ }^{*}$, with $\mathrm{x}_{i}{ }^{*}$ and $\mathrm{x}_{j}{ }^{*}$ as the ideal points of player $i$ and $j$ respectively, $i, j \in \mathrm{N}^{2}$ The agent is authorized to set a policy along the policy dimension $X$, and it proposes a regulatory policy that can only be changed if the legislature enacts a bill. The agent's proposal has to be considered as the point from which the legislature may propose a change. If the legislature fails to adopt a bill, the initial agent proposal will be implemented and can thus be regarded as the current state of affairs or status quo. Let $\mathrm{x} \in \mathrm{X}$ be the proposal of the agent. Now, define the set $\mathrm{I}_{i}(\mathrm{x})=$ $\left\{\mathrm{y} \mid \mathrm{U}_{i}(\mathrm{y})=\mathrm{U}_{i}(\mathrm{x}), \mathrm{y} \in \mathrm{X}, \mathrm{y} \neq \mathrm{x}\right\}$. As a consequence of single-peakedness, this set is a singleton set. The unique element of this set can be called player $i$ 's point of indifference to $\mathrm{x}$, which will be denoted as $i(\mathrm{x})$. The preference set of a player $i$, that is, the set of points a player strictly prefers to $\mathrm{x}$, is defined as $P_{i}(x)=\left\{y \mid U_{i}(y)>U_{i}(x), y \in X\right\}$; a weak version of the preference set is $\mathrm{R}_{i}(\mathrm{x})$ which is defined as $\left\{\mathrm{y} \mid \mathrm{U}_{i}(\mathrm{y}) \geq \mathrm{U}_{i}(\mathrm{x}), \mathrm{y} \in \mathrm{X}, \mathrm{y} \neq \mathrm{x}\right\}$.

Players are assumed to have complete and perfect information: that is, the preferences of players, the structure of the game, and the fact that players behave in a rational way are assumed to be common knowledge, while for every stage of the game only one player is allowed to make a move. None of the players prefers its decision to be overturned. This preference can be viewed as imposing some cost on a proposal that is not the final outcome of the decision making process (see, for instance, Ferejohn and Shipan, 1990: 6). These costs are assumed to reduce the final payoff to a player. If a unique equilibrium outcome exists, which can be reached either by proposing this policy or by having another player reverse its decision and proposing the 
final outcome, a player will prefer the first alternative. Finally, decisions are assumed to be made in a sequential way: that is, there exists a set of procedural rules that specify the order in which players are allowed to make a move. Given these assumptions, the equilibrium concept of subgame perfectness can be used, which provides a unique Nash equilibrium for each game discussed in this paper.

Now assume a simple political system in which an agent is allowed to propose a new regulatory policy, while a unicameral legislature may respond to this policy by introducing a bill. Let $\mathrm{x}_{a}{ }^{*}$ be the agent's ideal point, and $\mathrm{x}_{p}{ }^{*}$ be the ideal point of the median member of the legislature. Policies in this system are the result of a two-stage game in which the legislature moves last. The equilibrium outcome will be equivalent to $\mathrm{x}_{p}{ }^{*}$. Since the median legislator will propose and approve a bill $\mathrm{y}=\mathrm{x}_{p}{ }^{*}$ in the last stage, the agent is induced to select this policy as well. Any other proposal will yield a lower payoff, since the legislature will reverse the agent's initial decision if it is not equivalent to the policy $\mathrm{x}=\mathrm{x}_{p}{ }^{*}$. In this example, the equilibrium policy will be equivalent to the ideal point of the median member in the legislature, independently of the agent's preference. So the legislature completely controls policymaking. The set of politically feasible agent policies, that is, the set of policies from which the agent may make its choice without triggering legislative action, is a singleton set. This can be associated with a situation in which the agent has no discretion at all. However, in most games that will be analyzed in this paper, the set of feasible agent policies will be larger. The distance between the most extreme elements from the set of feasible agent policies in $\mathrm{X}$ will be regarded as a measure of discretion. The larger this distance, the larger is the discretion of the agent. In this view, agent discretion and agent preferences are treated as analytically distinct concepts. Discretion describes the set of potential policies the agent may choose, while the agent's actual choice of a policy from this set is based on its preferences. Consequently, an agent may select a policy close to the ideal point of the decisive legislator, not because it is induced to do so, but because the agent prefers this policy to all other feasible policies. ${ }^{3}$

Most legislatures have a much more complex institutional structure than is assumed in the example above. In this paper, I will distinguish the following lawmaking powers:

1. initiation power: a player $i$ is allowed to make a proposal, shaped as a bill, in order to change the agent's policy $\mathrm{x}$;

2. amendment power: if legislation is initiated, a player $i$ may change the bill by introducing and approving motions; and

3. veto power: a bill has to be approved by player $i$ before it can be enacted. 
These powers can be attributed to players in various ways: some powers are concentrated with one player, while others are shared. If a power is exclusively allocated to a player, this player is said to have monopoly power. On the one hand, if some players may only use a specific power, these players can be called specialized players.

The most interesting forms of monopoly power are related to the power to initiate and amend. A player with monopoly initiation power is usually identified as a gatekeeper: no change in the agent's policy may occur unless this player issues a proposal. ${ }^{4}$ Given the opportunity to amend a proposal in a subsequent stage, a gatekeeper may only affect public policies by keeping its gates closed and not introducing any legislation. The moment it initiates a legislative process, players with amendment and veto power will shape the final proposal. ${ }^{5}$ Examples of a gatekeeper are the European Commission, which has monopoly initiation power in the legislative process of the European Union, and legislative committees in the U.S. Congress. If a player has monopoly initiation and amendment power, it may act as an agenda setter. ${ }^{6}$ Such a player not only decides whether or not legislation will be introduced, it also determines the final proposal. This makes an agenda setter rather powerful, since it is able to force a player with veto power to agree with a different proposal than the one it actually prefers. In some instances, when the European Council is not able to reach unanimous consent, the European Commission is able to act as an agenda setter in the legislative process. Its proposals are only subjected to a veto of the Council and the European Parliament.

Some of these powers, and veto power in particular, can be nested in the sense that one player's use of power is contingent upon the use of the same power by another player. A rather common arrangement is a "veto-on-aveto", that is, a player is empowered to use its veto based on the veto of another player. The effect is that the initial veto will be neutralized. This "second-order" veto will be called override power. Given the possibility of override, two different types of veto power can be distinguished. A player has absolute veto when no player is empowered to neutralize its veto. In case of a suspensive veto, some player may reverse a veto made by another player in a previous stage of the game. ${ }^{7}$

\section{Policy games}

The distribution of initiation, amendment, veto and override power to players determines the structure of the legislative process. These different legislative structures form the basis of the various policy games, which can be labeled as follows: ${ }^{8}$ 
Table 1. Distribution of lawmaking powers in different policy games

\begin{tabular}{lllll}
\hline & \multicolumn{2}{l}{ Power } & \\
\cline { 2 - 5 } Policy game & Initiation & Amendment & Veto & Override \\
\hline 1. Veto game & \multicolumn{2}{c}{ Agenda setter } & Veto player & no \\
2. Override game & \multicolumn{2}{c}{ Agenda setter } & Veto player & Override player \\
3. Gatekeeping game & Gatekeeper & Legislator & no & no \\
4. Gatekeeping-veto game & Gatekeeper & Legislator & Veto player & no \\
5. Gatekeeping-override game & Gatekeeper & Legislator & Veto player & Override player \\
\hline
\end{tabular}

1. a veto game, which typifies a legislative structure in which one player has monopoly initiation and amendment power and thus may act as an agenda setter, while one or more other players have veto power. In other words, in a veto game an agenda setter determines a final bill $\mathrm{y}$, which is subjected to an absolute veto of the other players in the legislative process;

2. an override game, which can be regarded as a variation of a veto game, as veto power is restricted to a suspensive veto. If a player vetoes a bill $y$, an override player may decide whether or not it will neutralize this veto and let the bill stand;

3. a gatekeeping game, in which one or more players are introduced that only have initiation power. These players decide whether or not a legislative process is started;

4. a gatekeeping-veto game, which is a basic gatekeeping game extended with one or more players with veto power; and,

5. a gatekeeping-override game, which characterizes a structure in which the distinguished lawmaking powers are assigned to specialized players. This structure combines the features of an override game and a gatekeeping game.

The distribution of lawmaking powers that can be associated with these games is given in Table 1.

\subsection{Veto game}

The basic veto game consists of the following three stages: in the first stage the agent proposes a new policy $\mathrm{x}$. In the second stage players with monopoly initiation and amendment power - the agenda setters in this game - consider the proposal of the agent. They may accept the agent policy or propose a new policy in the form of a final bill $y$. In the third stage, a player with veto power 
decides whether or not it will accept the bill $\mathrm{y}$ given the existing policy $\mathrm{x}$. For simplicity, and if more than one player has veto power, these players are considered to be members of a "committee" which has to decide on the bill unanimously. Only when all "committee" members agree upon y and choose not to use their veto power, can $\mathrm{x}$ be replaced. If at least one of these players does not strictly prefer the bill, it will use its veto, and the agent can continue to implement $\mathrm{x}$. $^{9}$

Let player $p \in \mathrm{L}$ be the median legislator, whose preference is decisive in a majority vote in the legislature. In this game, a legislative process is only initiated when the median legislator is able to formulate a bill that is preferred to $\mathrm{x}$ by this player and those players which have veto power. Formally, legislation is initiated if $\mathrm{y} \in \mathrm{R}_{v}(\mathrm{x}) \cap \mathrm{P}_{p}(\mathrm{x})$ with $v \in \mathrm{M}$ as the player with veto power. ${ }^{10}$ The intersection of both sets, $\mathrm{R}_{v}(\mathrm{x}) \cap \mathrm{P}_{p}(\mathrm{x})$, will be called the set of politically feasible bills, since it contains only those bills that will be accepted in a legislative process. If more than one veto player is involved, define the set $\mathrm{R}^{v}=\bigcap_{i} \mathrm{R}_{i}(\mathrm{x})$ for all $i \in \mathrm{V} . \mathrm{V}=\left\{v_{1}, \ldots v_{v}\right\} \subset \mathrm{M}$. Then the set of feasible bills is simply $\mathrm{R}^{v} \cap \mathrm{P}_{p}(\mathrm{x})$ for $v$ players with veto power. The problem the agent faces is to select a proposal that results in an empty set of feasible bills and is as close as possible to its ideal point.

Knowing the responses of the legislators and the veto players, the agent selects its best proposal such that $\mathrm{R}^{v} \cap \mathrm{P}_{p}(\mathrm{x})=\emptyset$. From the definition of the preference set and the assumption of single-peaked preferences, it follows directly that the set of feasible bills is empty when the agent selects a policy equivalent to the ideal points of one of the most extreme players, or any point between these two players. Define $\mathrm{x}_{l}{ }^{*}=\min \left\{\mathrm{x}_{i}{ }^{*}\right\}$ and $\mathrm{x}_{r}{ }^{*}=\max \left\{\mathrm{x}_{i}{ }^{*}\right\}$ for all $i \in\{p\} \cup \mathrm{V}$, so this result can be summarized as follows:

Proposition 1. In a veto game, the equilibrium policy $\mathrm{x}$ is the point in the interval $\left[\mathrm{x}_{l}{ }^{*}, \mathrm{x}_{r}{ }^{*}\right]$ which the agent prefers most. ${ }^{11}$

This result shows that agent discretion is a result of the conflict of interest among the players with lawmaking powers. When the median legislator proposes legislation, some players may agree on the bill, while others disagree. Their support for the bill depends on the new agent policy, which forms the starting point for the legislative process. If the new agent policy falls between the policy positions of these players, a conflict of interest always exists. The reason for this is that some players will prefer a change in a direction that makes other players worse off. Points that express this conflict are found in the interval $\left[\mathrm{x}_{l}{ }^{*}, \mathrm{x}_{r}{ }^{*}\right]$, which forms the set of politically feasible agent policies. For agent policies that are located in this interval a player always exists that prefers a direction of change others will oppose, so 
Diagram 1. A preference configuration for players in a veto game

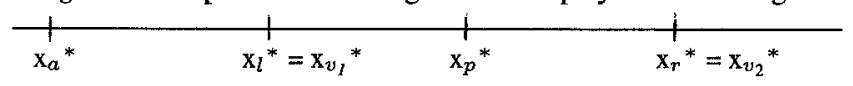

any new bill that aims to change the agent policy will be vetoed. The agent implements its own ideal point. If its ideal point is located outside the interval as indicated in Diagram 1, the agent selects $\mathrm{x}=\mathrm{x}_{l}{ }^{*}$ as its policy. ${ }^{12}$

The distance between the most extreme points in this interval, that is, between $\mathrm{x}_{l}{ }^{*}$ and $\mathrm{x}_{r}{ }^{*}$, will be used as an indicator of agent discretion. A direct implication of Proposition 1 is that the discretion of the agent becomes larger the more the preferences of the extreme players with lawmaking power differ. ${ }^{13}$ A possible variation of a veto game is one in which the legislator having initiation and amendment power also has veto power. However, the additional veto power of this player will not affect the set of feasible bills and thus agent discretion. The agent still has to select its best policy from the interval indicated.

\subsection{Override game}

An override game can be regarded as an extension of a veto game: after the first three stages described in the previous section, a player with override power decides in the last stage whether or not it will neutralize a veto and allow the final bill, $y$, to be implemented as the new public policy. Such a player can be associated with a legislative committee or a joint session of both chambers in a bicameral system that has the power to override an executive veto by majority. If the player with override power does not strictly prefer the vetoed bill in the third stage, it will not override the veto, and the agent can continue to implement its policy $x$.

If a player has override power, the median legislator, $p$, will initiate legislation if a bill yields a strict Pareto improvement for itself and the player (or players) with veto power or the player with override power. Unanimous consent of the veto players is no longer a necessary condition for legislative initiative, since a veto can be overridden. Let $v$ and $o$ denote the players with veto and override power, respectively. Now, policies in the set $\mathbf{R}_{v}(x) \cup \mathrm{P}_{o}(\mathrm{x})$ are "veto proof", that is, will not be vetoed by $v$ in the third stage of the game. If more veto players are involved, the set $\mathrm{R}^{v} \cup \mathrm{P}_{o}(\mathrm{x})$ contains the veto proof proposals. Knowing this response, the legislator will select its most preferred policy from this set. The problem the agent faces is to select a policy $\mathrm{x}$ that will be preferred by the legislator to the outcome of a legislative process, and is as close as possible to the agent's own ideal point. 
Given the response of the veto players and the override player, the legislator will not introduce a new bill if the set of feasible bills is empty, that is, if $\mathrm{P}_{p}(\mathrm{x}) \cap\left(\mathrm{R}^{v} \cup \mathrm{P}_{o}(\mathrm{x})\right)=\emptyset$. This offers the agent the opportunity to select its best proposal such that it empties this set. Assume, without loss of generality, that $\mathrm{x}_{p}{ }^{*} \geq \mathrm{x}_{o}{ }^{*}$, then the agent selects the following policy:

Proposition 2-1. In an override game, the equilibrium policy $\mathrm{x}$ is the point in the interval $\left[\max \left\{\mathrm{x}_{o}{ }^{*}, \mathrm{x}_{l}{ }^{*}\right\}, \mathrm{x}_{p}{ }^{*}\right]$ which the agent prefers most if $\mathrm{x}_{p}{ }^{*}>\mathrm{x}_{l}{ }^{*}$, or it is $\mathrm{x}_{p}{ }^{*}$ if $\mathrm{x}_{p}{ }^{*}=\mathrm{x}_{l}{ }^{*}$.

Override power reduces the agent's ability to select different policies for it neutralizes the power of at least some of the veto players. These veto players will no longer block new legislation, otherwise their veto will be overridden. Thus, the legislator will be able to successfully introduce a bill in a larger number of cases. The override player will only use its power when a veto leads to the blocking of a bill that is preferred to the agent policy. The extent to which this player intervenes and affects agent discretion thus depends on its position vis- $\grave{a}$-vis the legislator and the veto players. If veto players are located at the same side of the legislator as the override player, agent discretion will be smaller the closer the distance is between the override player and the legislator. If the override player is located at the side of the median legislator opposite to the veto players, the set of feasible agent policies is a singleton, and the agent does not have any discretion.

The proposition also has an important implication for a game in which the player with initiation and amendment power has override power. In that case, the legislator, $p$, and the override player, $o$, are the same. Then, as the proposition indicates, the equilibrium outcome is equivalent to the policy $\mathrm{x}_{p}{ }^{*}$, independent of the preferences of the veto players. Note that in this case the agent no longer has discretion and is induced to implement the policy the legislator prefers most.

Proposition 2-1 assumes a single override player whose authority is not affected by the location of the agent policy along the policy dimension. In most political systems, however, a veto can only be overridden by a special majority in the legislature. For instance, in the U.S., a two-thirds majority in both chambers of Congress is required to override a veto of the president. In the European Union, and following the cooperation procedure, only unanimity in the Council may overrule a veto of the European Parliament. In these cases, two potential positions for a decisive override player exist, which may play a role in the policy process and affect agent discretion. To introduce this form of override power to the basic override game, assume that a veto can be overridden by a special majority, $s$, in the legislature with $l$ members. 
Furthermore, $[(l / 2)+1]<s \leq l$. Let $o_{l}$ and $o_{r}$ be the legislators whose ideal points are located such that $s$ ideal points of members of the legislature are found to their right and left, respectively. By definition, $\mathrm{x}_{o_{l}}{ }^{*} \leq \mathrm{x}_{p}{ }^{*} \leq \mathrm{x}_{o_{r}}{ }^{*}$, with $p$ as the median legislator. Since override power is only relevant if the agent policy is not found in the interval $\left[\mathrm{x}_{o_{l}}{ }^{*}, \mathrm{x}_{o_{r}}{ }^{*}\right],{ }^{14}$ the following two cases have to be distinguished:

1. the case of a united legislature, that is, $\mathrm{x}_{a}{ }^{*}<\mathrm{x}_{o_{l}}{ }^{*}$ or $\mathrm{x}_{a}{ }^{*}>\mathrm{x}_{o_{r}}{ }^{*}$ : since the agent prefers to propose a policy outside the interval $\left[\mathrm{x}_{o_{l}}{ }^{*}, \mathrm{x}_{o_{r}}{ }^{*}\right]$, the legislature will be able to form a special majority against this policy, which forms the status quo, and to override a veto; and

2. the case of a divided legislature, that is, $\mathrm{x}_{o_{l}}{ }^{*} \leq \mathrm{x}_{a}{ }^{*} \leq \mathrm{x}_{o_{r}}{ }^{*}$ : the agent now prefers a policy that divides the members of the legislature who are necessary to form a special majority. Since the legislature is not able to form a special majority against the agent policy, it cannot override a veto.

These two cases show that override power is conditional to the location of the agent policy. In case of a united legislature, a player exists that can override a veto, which can be either $\mathrm{x}_{O_{l}}{ }^{*}$ of $\mathrm{x}_{O_{r}}{ }^{*}$. Since this player will respond to vetoes in a similar way as the override player described before, the result as reported in Proposition 2-1 can be applied. If the legislature is divided, a special majority cannot be formed, and veto players have an absolute veto. Policymaking can now be typified as a simple veto game in which the agent is able to select its best policies from the interval $\left[\mathrm{x}_{l}^{*}, \mathrm{x}_{r}{ }^{*}\right]$, as Proposition 1 indicates. Combining these earlier results, the agent selects the following equilibrium policy:

Proposition 2-2. In an override game in which a special majority is required to override a veto, the equilibrium policy $\mathrm{x}$ is the point in the interval $\left[\max \left\{\mathrm{x}_{o_{l}}{ }^{*}, \mathrm{x}_{l}{ }^{*}\right\}, \min \left\{\mathrm{x}_{o_{r}}{ }^{*}, \mathrm{x}_{r}{ }^{*}\right\}\right]$ which the agent prefers most.

Agent discretion is now determined by the relative positions of the override player and the most extreme veto player. If the agent holds an extreme position, as in Diagram 2, a special majority can be formed. The legislature can use its override power to neutralize vetoes of more extreme veto players, such as veto player $v_{1}$ in the diagram. A less extreme position, which can be associated with a position between the two potential override players, does not allow the legislature to form a special majority. The agent may select its most preferred point providing that the median legislator and the veto players are divided with regard to a change of this policy.

Two additional observations can be based on the result in Proposition 2-2. First, note that $\max \left\{\mathrm{x}_{o_{l}}{ }^{*}, \mathrm{x}_{l}{ }^{*}\right\} \geq \mathrm{x}_{l}{ }^{*}$ and $\min \left\{\mathrm{x}_{o_{r}}{ }^{*}, \mathrm{x}_{r}{ }^{*}\right\} \leq \mathrm{x}_{r}{ }^{*}$. So the set of feasible agent policies for this policy game is a subset of the set for a 
Diagram 2. A preference configuration for players in an override game

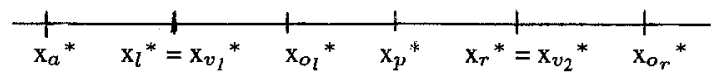

veto game. In other words, agent discretion in this version of an override game is thus equivalent to or smaller than discretion in a veto game. Second, since override power is based on special majority voting, agent discretion is affected by the special majority, $s$, that is required. The larger this special majority, assuming that some extreme veto player exists, the larger is agent discretion. From this perspective, a two-thirds majority to override a veto will be a more effective means to reduce agent discretion than unanimity.

\subsection{Gatekeeping game}

The structure of a basic gatekeeping game is as follows: in the first stage the agent proposes a new policy $x$. In the second stage a player with only monopoly initiation power considers the agent's proposal. This gatekeeper decides whether or not a legislative process is to be initiated. If it weakly prefers the proposal of the agent to the outcome of a legislative process, it will not release a bill, and the proposal of the agent will be implemented as the new public policy. If not, the gatekeeper proposes a bill which is submitted to the legislature. In the third and last stage, the legislature which has amendment power considers the gatekeeper's proposal. Legislators may vote on motions, using simple majority rule, which lead to the final bill, $y$.

Let $\mathrm{x}_{g}{ }^{*}, g \in \mathrm{N}$, be the ideal point of the gatekeeper $(p \neq g$, with $p$ as the median legislator). Without loss of generality, assume $\mathrm{x}_{g}{ }^{*} \leq \mathrm{x}_{p}{ }^{*}$. In the third stage, the legislature will enact $\mathrm{y}=\mathrm{x}_{p}{ }^{*}$ as the new public policy. The gatekeeper will not initiate a legislative process if the agent proposal is weakly preferred to the bill, that is, if $x \in \mathrm{R}_{g}(\mathrm{y})$. Knowing this, the agent selects its best policy that is equivalent to the gatekeeper's point of indifference to the final bill or the ideal point of the median legislator, or any point in between. ${ }^{15}$ See, for example, the preference configuration in Diagram 3 , which yields the equilibrium outcome $\mathrm{x}=g\left(\mathrm{x}_{p}{ }^{*}\right)$.

If more players with only initiation power are involved in the game- which implies that $g$ no longer has monopoly power - legislation will be initiated if at least one of these players prefers the bill to the agent policy. Two different cases have now to be distinguished: 
Diagram 3. A preference configuration for players in a gatekeeping game

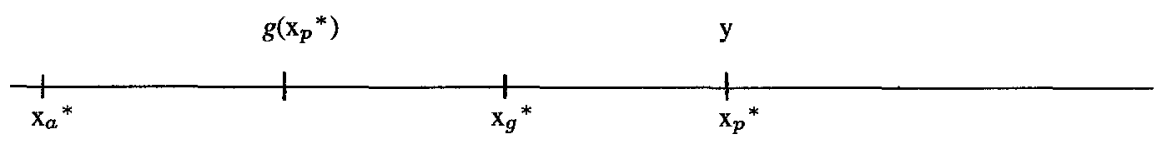

Diagram 4. A preference configuration for players in a gatekeeping game

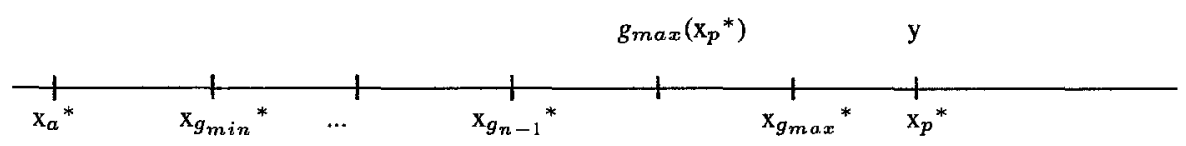

1. opposing gatekeepers, that is, the median legislator has a preference between at least two gatekeepers, and,

2. gatekeepers with common interests, that is, all gatekeepers are found to the left or to the right of the ideal point of the median legislator.

In the case of opposing gatekeepers, the agent is induced to propose a policy equivalent to the median legislator's ideal point, since any deviation from this point will lead to legislative initiative of one of the players with initiation power. A proposal $\mathrm{x}>\mathrm{x}_{p}{ }^{*}$ will lead to a response from the gatekeeper with an ideal point to the left of $\mathrm{x}_{p}{ }^{*}$; a proposal $\mathrm{x}<\mathrm{x}_{p}{ }^{*}$ will lead to a response from those with an ideal point to the right of $x_{p}{ }^{*}$. So, in this case, agent discretion is effectively reduced as a result of disagreement among gatekeepers about keeping their gates closed.

If, however, gatekeepers have common interests, that is, all their ideal points are on the same side of the ideal point of the median legislator, the agent has some discretion. It depends on the distance between the gatekeeper closest to the legislator, $p$. Only this gatekeeper is of relevance, since it will be the first player to prefer a bill to the agent proposal and thus to release new legislation. Given $\mathrm{x}_{g_{i}} \leq \mathrm{x}_{p}{ }^{*}$, this player can be defined as $\mathrm{x}_{g_{\max }}{ }^{*}=\max \left\{\mathrm{x}_{i}{ }^{*}\right\}$ for all $i \in \mathrm{G}, \mathrm{G}=\left\{g_{1}, \ldots g_{g}\right\} \subset \mathrm{M}$. Similarly, define $\mathrm{x}_{g_{\min }}{ }^{*}=\min \left\{\mathrm{x}_{i}{ }^{*}\right\}$. See the preference configuration in Diagram 4 . Given the preferences of these gatekeeping players, the agent may select a point in the interval $\left[g_{\max }\left(\mathrm{x}_{p}{ }^{*}\right)\right.$, $\left.\mathrm{x}_{p}{ }^{*}\right]$ as its policy. Since, in the diagram, $\mathrm{x}_{a}{ }^{*}<\mathrm{x}_{g_{\min }}{ }^{*}$, the equilibrium policy will be equivalent to the rightmost gatekeeper's point of indifference to $\mathrm{x}_{p}{ }^{*}$. So, assuming that $\mathrm{x}_{p}{ }^{*} \geq \mathrm{x}_{g_{\min }}{ }^{*}$, the following result holds.

Proposition 3. In a gatekeeping game, the equilibrium policy $x$ is 
(i) equivalent to the ideal point of the legislator, $\mathrm{x}_{p}{ }^{*}$, if $\mathrm{x}_{g_{\min }}{ }^{*} \leq \mathrm{x}_{p}{ }^{*} \leq$ $\mathrm{x}_{g_{\max }}{ }^{*}$, or

(ii) the point in the interval $\left[g_{\max }\left(\mathrm{x}_{p}{ }^{*}\right), \mathrm{x}_{p}{ }^{*}\right]$ which the agent prefers most if $\mathrm{x}_{p}{ }^{*}>\mathrm{x}_{g_{\max }}{ }^{*}$.

A gatekeeper, and particularly one with monopoly power, has a substantial effect on agent discretion. The gatekeeper cannot determine the policy that will be selected in the legislative process. It only faces a choice between two points: the new agent policy, which forms the status quo, or the outcome the legislature prefers. This restriction to the gatekeeper, provides the agent with substantial discretion, particularly when the gatekeeper and the median legislator hold rather divergent views. Note that the legislature is not able to change the gatekeeper's response by suggesting that it will implement a more favorable policy. Such a promise will not be credible (or subgame perfect) as long as this policy is not equivalent to the one the median legislator actually prefers.

\subsection{Combined games}

The games discussed so far can be combined such that a gatekeeper may initiate a legislative process. In this process, the median legislator may propose a bill to change the agent policy which is subject to a veto of one or more other players. These vetoes, for their part, can be reversed by a unique override player or a special majority in the legislature. The introduction of a gatekeeper to the veto and override games implies that the effect of a gatekeeper, who may decide not to release a bill, has to be added to the possibility that veto players will block new legislation. Since the gatekeeper will only release a bill if the outcome of a legislative process is strictly preferred to the new agent policy, the agent now has two options with regard to its policy choice. It can propose a policy that either is (weakly) preferred by the gatekeeper to the final outcome of a legislative process, y, or leads to an empty set of feasible bills. In each case, legislation will not be initiated. The gatekeeper does not initiate legislation, or the legislature is too divided to agree on a policy change. Formally, for a gatekeeping-veto game, the agent policy has to be selected such that $\mathrm{x} \in \mathrm{R}_{g}(\mathrm{y})$ or $\mathrm{R}^{v} \cap \mathrm{P}_{p}(\mathrm{x})=\emptyset$. This yields the following equilibrium outcome:

Proposition 4. In a gatekeeping-veto game, the equilibrium policy $\mathrm{x}$ is the point in

(i) the interval $\left[g\left(\mathrm{x}_{p}{ }^{*}\right), \mathrm{x}_{r}{ }^{*}\right]$ if $\mathrm{x}_{g}{ }^{*}<\mathrm{x}_{l}{ }^{*}$,

(ii) the interval $\left[\mathrm{x}_{l}{ }^{*}, \mathrm{x}_{r}{ }^{*}\right]$ if $\mathrm{x}_{l}{ }^{*} \leq \mathrm{x}_{g}{ }^{*} \leq \mathrm{x}_{r}{ }^{*}$, or 
(iii) the interval $\left[\mathrm{x}_{l}{ }^{*}, g\left(\mathrm{x}_{p}{ }^{*}\right)\right]$ if $\mathrm{x}_{g}{ }^{*}>\mathrm{x}_{r}{ }^{*}$.

which the agent prefers most.

Recall that $\mathrm{x}_{l}{ }^{*}$ and $\mathrm{x}_{r}{ }^{*}$ are the ideal points of the leftmost and rightmost players from $\left\{p, \mathrm{v}_{1}, \ldots v_{n}\right\}$, respectively. So, as the proposition indicates, the introduction of a gatekeeper in a veto game leads to additional discretion for the agent. This is a result of the fact that the gatekeeper takes only into account the outcome of a legislative process, and may decide to keep its gates closed if it prefers the agent policy.

A similar discretion increasing effect is found for a gatekeeping-override game. This is not surprising, since the introduction of an override player will only affect the extent to which a player can exercise its veto power. Since this mechanism has been discussed in Section 3.2, I will not pursuit a further discussion of these combined games. ${ }^{16}$

\section{Agent discretion and agent preferences}

Agent discretion is a result of the structural characteristics of the legislative process as well as the preferences of the legislative players. In order to compare the effect of institutional arrangements on agent discretion, player preferences have to be taken into account. For this comparison, I assume that: (1) the preferences of players are distinct, that is, for all players, $i, j \in \mathrm{N}, \mathrm{x}_{i}{ }^{*} \neq$ $\mathrm{x}_{j}{ }^{*}$; (2) players have symmetric preferences, that is, player $i$ is indifferent between $\mathrm{y}$ and $\mathrm{z}$ if $\left|\mathrm{y}-\mathrm{x}_{i}{ }^{*}\right|=\left|\mathrm{z}-\mathrm{x}_{i}{ }^{*}\right|$, for $\mathrm{y}, \mathrm{z} \in \mathrm{X}$; (3) the players' ideal points are distributed at equal distances, $d$, along the policy dimension $X$; and, (4) the preference configurations that are possible are equally probable. Furthermore, the number of players, and thus the number of available positions, will be restricted to six: a legislator, two veto players, a gatekeeper and two override players. ${ }^{17}$ Using these assumptions agent discretion can be expressed in terms of $d$ and computed for all possible configurations that satisfy the condition $\mathrm{x}_{o_{l}}{ }^{*} \leq \mathrm{x}_{p}{ }^{*} \leq \mathrm{x}_{o_{r}}{ }^{*}$. These results are summarized in Table 2 .

As expected, the results show that agent discretion is largest in those games in which a gatekeeper is involved. A gatekeeping-veto game yields the most discretion. Its mean value of 5.3 is the highest in the table. The least discretion is found in an override game with a unique override player, for which the average agent discretion is 1.1. Also note that for some preference configurations in this game the override player completely reduces agent discretion. This is indicated by a zero level of discretion, which occurs with a probability of $30 \%$. A veto game yields an intermediate level of agent discretion. It is higher than the discretion found for an override game, but lower than discretion in a gatekeeping game or any of the combined games. 
Table 2. Agent discretion in different games $(\mathrm{n}=120)$

\begin{tabular}{llccc}
\hline \multirow{2}{*}{ Game } & \multicolumn{4}{c}{ Agent discretion (in d; probability between brackets): } \\
\cline { 2 - 5 } & Mean* & $\begin{array}{l}\text { Standard } \\
\text { deviation }\end{array}$ & Minimum & Maximum \\
\hline 1. Override game: unique & 1.1 & .9 & $0(30 \%)$ & $3(7 \%)$ \\
2. Override game: special majority & 2.1 & .7 & $1(17 \%)$ & $3(27 \%)$ \\
3. Veto game & 3.3 & .9 & $2(20 \%)$ & $5(7 \%)$ \\
4. Gatekeeping game & 4.2 & 2.0 & $2(33 \%)$ & $8(10 \%)$ \\
5. Gatekeeping-override game: unique & 4.6 & 1.9 & $2(18 \%)$ & $8(10 \%)$ \\
6. Gatekeeping-override game: special & & & & \\
$\quad$ majority & 4.9 & 1.8 & $2(3 \%)$ & $8(10 \%)$ \\
7. Gatekeeping-veto game & 5.3 & 1.7 & $3(10 \%)$ & $8(17 \%)$ \\
\hline
\end{tabular}

${ }^{*}$ Using a two-tailed difference of means test, discretion significantly differs between these games at the .01 level.

The fact that structural characteristics and preferences codetermine the equilibrium outcome offers two additional ways for a legislature to affect agent policymaking. First, agent discretion can be reduced by affecting the preferences of the other players that are involved in a legislative process, in particular if they are members of a subset of the legislature. If, for instance, override power can be exercised by a special majority, the leadership of the majority party or some coalition of parties may reduce discretion by increasing party discipline. However, such an effort is only effective if the agent has a rather extreme preference and is induced to select the ideal point of the decisive override player as its policy. Another important player can be a legislative committee that may act as a gatekeeper. As indicated, the agent will have substantial discretion if the gatekeeper has a relatively extreme preference. The dominant legislative coalition will therefore have an incentive to assign members to a committee so that it resembles their preferences as closely as possible. If this coalition is successful, legislative committees will not be preference outliers, but will be expected to reflect the preferences of those who are in power. This tendency might be mitigated by the agent, as the "capture" theory of legislative committees suggests. The agent may provide committee members with special favors, which cause their preferences to shift away from the dominant coalition and in the direction of the agent. However, this argument only holds when at least two conditions are met. First, the agent must have an extreme preference, otherwise it does not have an incentive to affect committee preferences. Second, the agent must be able to shift committee preferences beyond the ideal points of the 
relevant veto or override players in a gatekeeping-veto or a gatekeepingoverride game. If these players have rather heterogenous preferences, and if affecting committee preferences is rather costly, it is unlikely that the agent will succeed.

Second, the legislature may try to affect agent preferences and not agent discretion. Discretion points to the agent's power to select different policies, while agent preferences determine its choice from a set of feasible alternatives. So far, only agent discretion has been analyzed, and it is assumed that agent preferences may vary along the relevant policy dimension X. However, if the dominant legislative coalition is able to pull agent preferences closer to its ideal point, the agent will select and implement a policy that is closer to the preferences of this group, despite the existence of a substantial amount of discretion. The relationship between an agent and the legislature is a matter of design, for which various arrangements can be chosen. Focusing on their dependency on legislative preferences, at least two types of agents can be distinguished. The first type are "dependent" agents who are appointed by the legislature. The preferences of these agents can be directly affected by the legislature. Examples are political appointments of board members or other officials of U.S. agencies, and the political selection of ministers in cabinet governments in Western Europe. Despite the differences between these political systems, the selection of agency heads and cabinet ministers fulfills the same function of reducing the distance between agent policies and the preferences of those who are in power. The second type are "independent" agents, who are not selected or appointed by the legislature. As a consequence their preferences either cannot be controlled by the legislature, or they can be controlled, but only at a high cost. Examples of this type are municipal councils to which central government has delegated policymaking powers, or public bodies controlled by national industries and labor unions. The question now arises to which type of agent the legislature prefers to delegate its policymaking power.

Two different views must be distinguished in regard to this question. The first view is that of the current legislative coalition that dominates parliament or Congress. This coalition prefers "direct" control of the preferences of the existing agencies, since it will temporarily lead to agent compliance and regulatory policies close to the preferences of important groups of voters from which the coalition receives its support. However, as the coalition loses its power, policies will change to reflect the preferences of a new coalition. The second view is that of the legislative coalition that establishes an agent. Agent design, and the way in which agent preferences are shaped, can be regarded as a way to secure a policy agreement of the initial coalition against future changes in political power (Moe, 1990). "Direct" control and the creation 
of "dependent" agencies are not effective means since they allow future coalitions to affect agent preferences. The initial coalition therefore has an incentive to create an "independent" agent to protect an agreement against future change. Given these views, a potential conflict exists between the demands of different legislative coalitions over time. If the initial coalition is successful in designing an "independent" agent, a substantial difference may exist between agent preferences and the preferences of the current legislative coalition.

Agent discretion now appears to fulfill different political functions depending on the dominant coalition taken into account. From the perspective of the current coalition, discretion is highly problematic, since it causes the agent policy to differ from the one preferred by the legislature. However, from the perspective of the initial coalition, discretion is a necessary condition for the proposal and implementation of policies that serve the best the interests of specific and favored groups of voters. Moreover, any deviation from the preferences of future legislative coalitions will be the intended result of agent design.

\section{Conclusions}

The analysis in this paper shows that an agent may have substantial discretion as a result of the structure of the legislative process. Agent discretion, as indicated by the set of politically feasible agent policies, arises when the players in the legislature are incapable of changing the agent's policy. This property need not be restricted to only one specific policy. It may hold for a wide range of different policies depending on the distribution of lawmaking powers to different players.

The analysis indicates that the more lawmaking power is differentiated and assigned to specialized players, the larger is the discretion of the agent. In particular, the differentiation of initiation and amendment power and the allocation of these powers to specialized players introduces a gatekeeper into the legislature process. This may provide the agent with substantial discretion. Similarly, the introduction of veto power and its assignment to a separate veto player also increases agent discretion. Agent discretion will be even larger if veto power is allocated to different veto players with heterogenous preferences. An illustration is the decision making process in the European Union under some of its decision making procedures, in which each Council member has a veto and is able to block policy change. The traditional argument in public administration literature is that differentiation and specialization within the legislature will increase political control over bureaucracy (see, for instance, Peters, 1989). However, the analysis in this paper shows that 
this will have the opposite effect. It will lead not to less discretion, but to more, since the introduction of more players with specific powers will make it much more difficult to find a bill to change the current agent policy that is preferred by all these players.

Agent discretion can be reduced by combining initiation, amendment and veto powers, and by reducing the number of players. The introduction of override power can also be considered when discretion is primarily based on veto power. These results have important implications for the reform of government institutions. First, the delegation of legislative oversight to a committee or a cabinet does not necessarily induce the agent to implement a policy closer to the preferences of the median member in the legislature. If such a player may act as a gatekeeper, this arrangement will lead to more agent discretion rather than less. The sharing of initiation power or the attribution of additional powers to the gatekeeper can be a way to reduce its effect on agent discretion. Second, the introduction of override power may decrease agent discretion, especially if the override player has a preference close to the median voter in the legislature. This can, for instance, be achieved by allowing the legislature to override executive vetoes. The smaller the special majority needed to override a veto, the closer the preference of the override player to the median representative and therefore, the smaller the discretion of the agent becomes. Another option is to assign override power to a separate voting body, which decides by majority.

The analysis in this paper also shows that the effects of different institutional arrangements on agent policymaking are not always empirically observable. The arrangements analyzed in this paper determine the structure of a legislative process in which players decide whether or not to change the policy that is proposed by the agent. Besides the sequence of play and the actions available to players, preferences also matter. Depending on these preferences, the agent can be restricted to the same set of feasible policies so that it will select equivalent policies independently of the arrangement that is used. However, this observation does not imply that structural characteristics do not matter. Their potential effect can be quite different and may become empirically observable when preferences change and the agent selects a new policy. Agent discretion may then substantially differ among arrangements leading to dissimilar public policies.

The distinction between agent discretion and agent preferences allows us to explain some of the dynamics of agent policymaking. ${ }^{18}$ First, agent policymaking can lead to inertia, since the agent does not always respond to preference changes in the legislature. Inertia may arise when the agent has a moderate preference, that is, the agent's ideal point is located in the set of feasible agent policies. As long as preference changes in the legislature do 
not reduce this set beyond the agent's ideal point, the agent is not induced to alter its policy. Second, agent policymaking can lead to biased policies, which deviate from the preferences of most representatives in parliament or Congress. If the agent has an extreme preference, that is, an ideal point that is not in the set of feasible policies, it will select an extreme policy from this set. The analysis shows that biased policies are not only a result of extreme agent preferences, but also a consequence of substantial agent discretion. Finally, agent policymaking can lead to sudden and discontinuous policy changes. If the agent has a moderate preference, it can be induced to change its policy when the set of feasible policies is reduced so that it can no longer select its ideal point. After a period of inertia, the agent will suddenly implement a new public policy. This response is not a result of changing agent preferences, but critical preference changes in the legislature. Similarly, policies may become rigid after a period of policy change when preference changes in the legislature have enlarged the set of feasible policies so that it includes the ideal point of the agent.

The results and implications of this paper are limited in the sense that one specific form of discretion is analyzed in a one-dimensional outcome space. If a multi-dimensional outcome space is taken into account, then additional agent discretion will arise. The legislature as a voting body will be confronted with multiple outcomes that can be supported with a majority instead of only one. This increases the agent's prospects for selecting its most preferred policy. Furthermore, the paper focuses on structure-induced discretion in a complete information setting. An extension is to analyze agent behavior in an incomplete information setting in which information-induced discretion also plays a role. The effects of this form of discretion can be mitigated by arrangements that change the incentives to the agent or reduce the cost of information to the legislature. However, as in a complete information setting, the agent can continue to employ the opportunities that are a result of the structure of the legislative process.

\section{Notes}

1. Using Eskridge and Ferejohn's (1992) model of court review, the court is assumed to be able to "reformulate" the agent policy by reinterpreting the "status quo" in the second stage and before the start of a legislative process. Then the court will select a policy that is as close as possible to its ideal point and meets the condition of being invulnerable to legislative initiative. Knowing this response, the agent selects a policy that does not lead to court or legislative action. This implies that the agent is induced to select the court's policy choice independently of its own preference.

2. Since players have single-peaked preferences along a single dimension, the well-known median voter theorem (Black, 1987: 18) applies if a decision has to be made on the basis of majority rule. 
3. The notion of discretion differs from the one employed by Calvert, McCubbins, and Weingast (1989: 589). In their model the executive and the legislature first appoint an agent, which then selects a policy that is subjected to a veto of both the executive and the legislature. Discretion is then defined as the departure of agent decisions from the position agreed upon by the executive and the legislature at the time of appointment. First, discretion as defined by Calvert, McCubbins, and Weingast is a distance between an initial position and the agent policy choice. In this view, discretion is determined by the agent's actual choice, and it is not its power to choose different policies. Second, they focus on information-induced discretion. In their model discretion only arises when the executive and the legislature are uncertain about the true preferences of the agent at the time of its appointment.

4. See also Denzau and Mackay (1983: 742), who formally represent a gatekeeper with the condition that if this player proposes no change in the status quo, then the legislative outcome is the status quo.

5. Shepsle and Weingast (1987: 90) therefore associate monopoly initiation power with an ex ante veto, and they show that the proposal of the gatekeeper can easily be rolled from the floor. Note that in this paper veto power will be associated with an ex post veto.

6. See Romer and Rosenthal $(1978,1979)$ and Denzau and Mackay (1983) for an analysis of agenda setting power.

7. Note that override power need not apply to all vetoes in a game. At this point a distinction can be made between general override power, which applies to all vetoes from previous stages of a game, and restricted override power which only applies to vetoes of some but not all veto players. Since I am not aware of a political system in which some player has restricted override power, this power will not be analyzed in this paper.

8. See also Steunenberg (1994), for discussion of a veto and a gatekeeping game.

9. A different representation of this game is to assume that each player with veto power is allowed to make a move in the third stage or in one of its successors. Then, given $n$ players with veto power, the number of stages will be $n+2$. Evidently, this game yields the same equilibrium as the one described.

10. If, for instance, veto power is formally a power of one of the chambers in the legislature, which decides using majority rule, its median member will be the veto player.

11. See the Appendix, for a proof.

12. Note that, for simplicity, the preference configuration in the diagrams is based on a political system with only two veto players. However, the results derived in this paper hold for any number of veto players.

13. Tsebelis (1995) analyzes the role of veto players from a different perspective. In his view, veto players induce political stability in processes of statutory decision making. Stability will increase as the number of veto players with heterogenous preferences increases. In this paper, however, agent discretion and not necessarily stability will increase as the number of veto players with different preferences increases.

14. If a special majority has to be formed in both chambers of a bicameral legislature, as in the U.S., let $\mathrm{x}_{o_{l 1}}{ }^{*}$ and $\mathrm{x}_{o_{r l}}{ }^{*}$ be the ideal points of the representatives with $s$ ideal points of House members to their right and left, respectively. Similarly, define $\mathrm{x}_{o_{12}}{ }^{*}$ and $\mathrm{x}_{o_{r 2}}{ }^{*}$ for the Senate. Since a veto can only be overridden by a special majority in both chambers, only the most extreme member can be decisive. Define $\mathrm{x}_{o_{l}}=\min \left\{\mathrm{x}_{o_{l 1}}{ }^{*}, \mathrm{x}_{o_{l 2}}{ }^{*}\right\}$ and $\mathrm{x}_{o_{r}}{ }^{*}=$ $\max \left\{\mathrm{x}_{o_{r 1}}{ }^{*}, \mathrm{x}_{o_{r 2}}{ }^{*}\right\}$. Override power of the legislature is then only relevant if the agent policy is not found in the interval $\left[\mathrm{x}_{o_{l}}, \mathrm{x}_{o_{r}}\right]$.

15. Ferejohn and Shipan (1990: 6-8) established this result for the interaction between an agency, a congressional committee and the House.

16. As indicated in Section 3.2 two different types of override players can be distinguished: (1) a unique override player whose power does not depend on the location of the status quo, and (2) a conditional override player whose power depends on the possibility to form a special majority against the current agent policy. The next two propositions describe the equilibrium outcome for these two types of override players. 
Proposition 5-1. In a gatekeeping-override game with a unique override player, and for $\mathrm{x}_{p}{ }^{*} \geq \mathrm{x}_{o}{ }^{*}$, the equilibrium policy $\mathrm{x}$ is the point in

(i) the interval $\left[g\left(\mathrm{x}_{p}{ }^{*}\right), \mathrm{x}_{p}{ }^{*}\right]$ if $\mathrm{x}_{g}{ }^{*}<\max \left\{\mathrm{x}_{0}{ }^{*}, \mathrm{x}_{l}{ }^{*}\right\}$,

(ii) the interval $\left[\max \left\{\mathrm{x}_{\circ}{ }^{*}, \mathrm{x}_{l}{ }^{*}\right\}, \mathrm{x}_{p}{ }^{*}\right]$ if $\max \left\{\mathrm{x}_{o}{ }^{*}, \mathrm{x}_{l}{ }^{*}\right\} \leq \mathrm{x}_{g}{ }^{*} \leq \mathrm{x}_{p}{ }^{*}$, or

(iii) the interval $\left[\max \left\{\mathrm{x}_{o}{ }^{*}, \mathrm{x}_{l}{ }^{*}\right\}, g\left(\mathrm{x}_{p}{ }^{*}\right)\right]$ if $\mathrm{x}_{g}{ }^{*}>\mathrm{x}_{p}{ }^{*}$, which the agent prefers most.

Proposition 5-2. In a gatekeeping-override game in which a special majority is required to override a veto, the equilibrium policy $\mathrm{x}$ is the point in

(i) the interval $\left[g\left(\mathrm{x}_{p}{ }^{*}\right), \min \left\{\mathrm{x}_{o_{r}}{ }^{*}, \mathrm{x}_{r}{ }^{*}\right\}\right]$ if $\mathrm{x}_{g}{ }^{*}<\max \left\{\mathrm{x}_{o_{l}}{ }^{*}, \mathrm{x}_{l}{ }^{*}\right\}$,

(ii) the interval $\left[\max \left\{\mathrm{x}_{o_{l}}{ }^{*}, \mathrm{x}_{l}{ }^{*}\right\}, \min \left\{\mathrm{x}_{o_{r}}{ }^{*}, \mathrm{x}_{r}{ }^{*}\right\}\right]$ if $\max \left\{\mathrm{x}_{o_{l}}{ }^{*}, \mathrm{x}_{l}{ }^{*}\right\} \leq \mathrm{x}_{g}{ }^{*} \leq \min \left\{\mathrm{x}_{o_{r}}{ }^{*}\right.$, $\left.\mathrm{x}_{r}{ }^{*}\right\}$, or

(iii) the interval $\left[\max \left\{\mathrm{x}_{o_{l}}{ }^{*}, \mathrm{x}_{l}{ }^{*}\right\}, g\left(\mathrm{x}_{p}{ }^{*}\right)\right]$ if $\mathrm{x}_{g}{ }^{*}>\min \left\{\mathrm{x}_{o_{r}}{ }^{*}, \mathrm{x}_{r}{ }^{*}\right\}$, which the agent prefers most.

Proposition 5-2 includes both propositions derived by Ferejohn and Shipan (1990: 13) for the cases $\mathrm{x}_{a}{ }^{*}=\mathrm{x}_{l}{ }^{*}<\mathrm{x}_{g}{ }^{*} \leq \mathrm{x}_{o_{l}}{ }^{*}<\mathrm{x}_{p}{ }^{*}$ and $\mathrm{x}_{a}{ }^{*}=\mathrm{x}_{l}{ }^{*}<\mathrm{x}_{o_{l}}{ }^{*} \leq \mathrm{x}_{g}{ }^{*}<\mathrm{x}_{p}{ }^{*}$. In Ferejohn and Shipan's paper $l$ is the president with a suspensive veto, $g$ is a Congressional committee with gatekeeping power, $o_{l}$ is the decisive voter in the House in case of twothirds majority voting (that is, two-thirds of the ideal points of representatives are found to its right), and $p$ is the median House member. Note that Ferejohn and Shipan analyzed a limited number of possible preference configurations for a unicameral system. Spitzer (1990) extends this model and presents results for some more cases.

17. In an override game in which a special majority is required to override a veto the override player is $o_{l}$ or $o_{r}$. In an override game with unconditional override power, the unique override player is assumed to be similar to the leftmost player $o_{l}$.

18. See Congleton (1982), for a different approach to bureaucratic inertia and bias.

\section{References}

Banks, J.S. (1989). Agency budgets, cost information, and auditing. American Joumal of Political Science 33: 670-699.

Banks, J.S. and Weingast, B.R. (1992). The political control of bureaucracies under asymmetric information. American Journal of Political Science 36: 509-524.

Bendor, J., Taylor, S. and Van Gaalen, R. (1985). Bureaucratic expertise vs. legislative authority: A model of deception and monitoring in budgeting. American Journal of Political Science 79: 1041-1060.

Bendor, J., Taylor, S. and Van Gaalen, R. (1987). Politicians, bureaucrats, and asymmetric information. American Journal of Political Science 31: 796-828.

Black, D. (1987[1958]). The theory of committees and elections. Boston: Kluwer.

Breton, A. and Wintrobe, R. (1975). The equilibrium size of a budget-maximizing bureau: A note on Niskanen's theory of bureaucracy. Journal of Political Economy 83: 195-207.

Calvert, R.L., McCubbins, M.D. and Weingast, B.R. (1989). A theory of political control and agency discretion. American Journal of Political Science 33: 588-611.

Congleton, R. (1982). A model of asymmetric bureaucratic inertia and bias. Public Choice 39: 421-425.

Denzau, A.T. and Mackay, R.J. (1983). Gatekeeping and monopoly power of committees: An analysis of sincere and sophisticated behavior. American Journal of Political Science 27: 740-761. 
Eskridge, W.N. and Ferejohn, J. (1992). Making the deal stick: Enforcing the original constitutional structure of lawmaking in the modern regulatory state. Journal of Law, Economics, and Organization 8: 165-189.

Ferejohn, J. and Shipan, C. (1990). Congressional influence on bureaucracy. Journal of Law, Economics, and Organization 6 (Special Issue): S1-20.

Ferejohn, J. and Weingast, B.R. (1992). A positive theory of statutory interpretation. International Review of Law and Economics 12: 263-279.

Hill, J.S. (1985). Why so much stability? The impact of agency determined stability. Public Choice 46: 275-287.

Kapteyn, P.J.G. and VerLoren van Themaat, P. (1990). Introduction to the law of the European Communities: After the coming into force of the Single European Act. Deventer: Kluwer.

Kiewiet, D.R. and McCubbins, M.D. (1988). Presidential influence on congressional appropriations decisions. American Journal of Political Science 32: 713-736.

Macey, J.R. (1992). Organizational design and political control of administrative agencies. Journal of Law, Economics, and Organization 8: 93-110.

Matthews, S.A. (1989). Veto threats: Rhetoric in a bargaining game. Quarterly Journal of Economics 104: 347-369.

McCubbins, M.D. (1986). The legislative design of regulatory structure. American Journal of Political Science 29: 721-748.

McCubbins, M.D., Noll, R.G. and Weingast, B.R. (1987). Administrative procedures as instruments of political control. Journal of Law, Economics, and Organization 3: 243-277.

McCubbins, M.D., Noll, R.G. and Weingast, B.R. (1989). Structure and process, politics and policy: Administrative arrangements and the political control of agencies. Virginia Law Review 75: 431-482.

Miller, G. and Moe, T. (1983). Bureaucrats, legislators, and the size of government. American Political Science Review 77: 297-322.

Moe, T.M. (1990). Political institutions: The neglected side of the story. Journal of Law, Economics, and Organization 6 (Special Issue): S213-253.

Niskanen, W.A. (1971). Bureaucracy and representative government. Chicago: AldineAtherton.

Ordeshook, P.C. (1992). A political theory primer. New York: Routledge.

Ostrom, E. (1986). An agenda for the study of institutions. Public Choice 48: 3-25.

Peters, B.G. (1989). The politics of bureaucracy. New York: Longman.

Romer, T. and Rosenthal, H. (1978). Political resource allocation, controlled agendas, and the status quo. Public Choice 33: 27-43.

Romer, T. and Rosenthal, H. (1979). Bureaucrats versus voters: On the political economy of resource allocation by direct democracy. Quarterly Journal of Economics 93 : 561-587.

Shepsle, K.A. (1979). Institutional arrangements and equilibrium in multidimensional voting models. American Journal of Political Science 23: 27-60.

Shepsle, K.A. and Weingast, B.R. (1981). Structure-induced equilibrium and legislative choice. Public Choice 37: 503-519.

Shepsle, K.A. and Weingast, B.R. (1987). The institutional foundations of committee power. American Political Science Review 81: 85-104.

Spiller, P. and Gely, R. (1992). Congressional control of judicial independence: The determinants of U.S. Supreme Court labor-relations decisions: 1949-1988. Rand Journal of Economics 23: 463-492.

Spiller, P.T. and Spitzer, M.L. (1992). Judicial choice and legal doctrines. Journal of Law, Economics, and Organization 8: 8-46.

Spitzer, M.L. (1990). Extensions of Ferejohn and Shipan's model of administrative agency behavior. Journal of Law, Economics, and Organization 6 (Special Issue): S29-43.

Steunenberg, B. (1994). Regulatory policymaking in a parliamentary setting. In $\mathrm{Ph}$. HerderDorneich, K.-E. Schenk, and D. Schmidtchen (Eds.), Jahrbuch für neue politische Ökonomie, Band 13: Neue politische Ökonomie der Regulierung, Deregulierung und Privatisierung, 36-57. Tübingen: Mohr. 
Tsebelis, G. (1995). Decisionmaking in political systems: Veto players in presidentialism, parliamentarism, multicameralism, and multipartism. British Journal of Political Science 25: $289-325$.

Weingast, B.R. (1984). The congressional-bureaucratic system: A principal agency perspective (with applications to the SEC). Public Choice 44: 147-191.

Weingast, B.R. and Moran, M.J. (1983). Bureaucratic discretion or congressional control? Regulatory policymaking by the Federal Trade Commission. Journal of Political Economy 91: 765-800. 


\section{Appendix}

The following notation is used in this paper:

$\mathrm{x}$

$\mathrm{y}$

$i(\mathrm{x})$

$\mathrm{P}_{i}(\mathrm{x})$

$\mathrm{R}_{i}(\mathrm{x})$

$\mathrm{x}_{i}{ }^{*}$

$a$

$g$

$o$

$p$

$v$ policy proposal of an agent;

final bill proposed in a legislative process;

player $i$ 's point of indifference to $\mathrm{x}$;

the set of points a player $i$ strictly prefers to $\mathrm{x}$;

the set of points a player $i$ weakly prefers to $\mathrm{x}$;

ideal point of a player $i$;

agent;

gatekeeper, i.e., a player with initiation power;

override player, i.e., a player with override power;

legislator, i.e., a player with amendment and, in some games, initiation power;

veto player, i.e., a player with veto power.

Proof of Proposition 1 (veto game): The game can be solved using backward induction. Note that the veto players will not use their veto if $\mathrm{y} \in \mathrm{P}^{v}$, and the median legislator only initiates legislation if it can formulate a bill $\mathrm{y} \in \mathrm{R}^{v} \cap$ $\mathrm{P}_{p}(\mathrm{x})$. So the agent has to select $\mathrm{x}$ such that $\mathrm{R}^{v} \cap \mathrm{P}_{p}(\mathrm{x})=\emptyset$. Two cases need to be distinguished:

1. if $\mathrm{x}_{l}{ }^{*} \leq \mathrm{x}_{a}{ }^{*} \leq \mathrm{x}_{r}{ }^{*}$, the agent finds the other players located at both sides of its ideal point. So, $\mathrm{R}^{v}\left(\mathrm{x}_{a}{ }^{*}\right) \cap \mathrm{P}_{p}\left(\mathrm{x}_{a}{ }^{*}\right)=\emptyset$, and the agent selects $\mathrm{x}=$ $\mathrm{x}_{a}^{*}$.

2. if $\mathrm{x}_{a}{ }^{*}<\mathrm{x}_{l}{ }^{*}$, then $\mathrm{R}^{v}\left(\mathrm{x}_{a}{ }^{*}\right) \cap \mathrm{P}_{p}\left(\mathrm{x}_{a}{ }^{*}\right) \neq \emptyset$. The agent will not select its ideal point and is induced to propose $\mathrm{x}=\mathrm{x}_{l}{ }^{*}$. This policy is as close as possible to $\mathrm{x}_{a}{ }^{*}$ and leads to an empty set of feasible bills. A policy proposal closer to $\mathrm{x}_{a}{ }^{*}$ triggers legislative action, and it results in a less preferred outcome: assume that $\mathrm{x}<\mathrm{x}_{l}{ }^{*}$, so $l(\mathrm{x})>\mathrm{x}_{l}{ }^{*}$. Then the median legislator, $p, \mathrm{x}_{p}{ }^{*} \geq$ $\mathrm{x}_{l}{ }^{*}$, will set a statutory policy $\mathrm{y} \geq \mathrm{x}_{l}{ }^{*}$ and $\mathrm{y} \leq l(\mathrm{x})$ which is (weakly) preferred to $\mathrm{x}$ by all players $i \in\{p\} \cup \mathrm{V}$. Since $\mathrm{x}_{a}{ }^{*}<\mathrm{x}_{l}{ }^{*}$, and players do not prefer their decisions to be overturned, the agent prefers an outcome $\mathrm{x}=\mathrm{x}_{l}{ }^{*}$ to a statutory policy $\mathrm{y} \geq \mathrm{x}_{l}{ }^{*}$. A similar argument applies to $\mathrm{x}_{a}{ }^{*}>$ $\mathrm{x}_{r}{ }^{*}$.

Proof of Proposition 2-1 (override game, unique player): In the last stage the override player, $o$, decides whether or not to override a veto. A veto will not be overridden if $\mathrm{y} \in \mathrm{P}_{o}(\mathrm{x})$. In the third stage, the veto players decide whether or not to use their veto knowing the response of the override player. A veto will not be used if $\mathrm{y} \in \mathrm{R}^{v} \cup \mathrm{P}_{o}(\mathrm{x})$. In the second stage the median legislator only initiates legislation if it can formulate a bill $\mathrm{y} \in \mathrm{P}_{p}(\mathrm{x}) \cap\left(\mathrm{R}^{v} \cup \mathrm{P}_{o}(\mathrm{x})\right)$, 
which can be rewritten as $\left(\mathrm{P}_{p}(\mathrm{x}) \cap \mathrm{R}^{v}\right) \cup\left(\mathrm{P}_{p}(\mathrm{x}) \cap \mathrm{P}_{o}(\mathrm{x})\right)$. So the agent has to select a policy $\mathrm{x}$ such that $\left(\mathrm{P}_{p}(\mathrm{x}) \cap \mathrm{R}^{v}\right) \cup\left(\mathrm{P}_{p}(\mathrm{x}) \cap \mathrm{P}_{o}(\mathrm{x})\right)=\emptyset$. Note that $\mathrm{P}_{p}(\mathrm{x}) \cap \mathrm{R}^{v}=\emptyset$ if $\mathrm{x}$ is a point in the interval $\left[\mathrm{x}_{l}{ }^{*}, \mathrm{x}_{r}{ }^{*}\right]$. See Proposition 1. Similarly, $\mathrm{P}_{p}(\mathrm{x}) \cap \mathrm{P}_{o}(\mathrm{x})=\emptyset$ if $\mathrm{x}$ is a point in the interval $\left[\mathrm{x}_{p}{ }^{*}, \mathrm{x}_{o}{ }^{*}\right]$ or $\left[\mathrm{x}_{o}{ }^{*}\right.$, $\left.\mathrm{x}_{p}{ }^{*}\right]$. Recall that $\mathrm{x}_{l}{ }^{*}=\min \left\{\mathrm{x}_{i}{ }^{*}\right\}$ for all $i \in\{p\} \cup \mathrm{V}$ and does not include the override player, $o$. Furthermore, assume that $\mathrm{x}_{p}{ }^{*} \geq \mathrm{x}_{o}{ }^{*}$. The following cases have to be distinguished:

1. if $\mathrm{x}_{p}{ }^{*}>\mathrm{x}_{l}{ }^{*}$, the intervals $\left[\mathrm{x}_{l}{ }^{*}, \mathrm{x}_{r}{ }^{*}\right]$ and $\left[\mathrm{x}_{o}{ }^{*}, \mathrm{x}_{p}{ }^{*}\right]$ overlap. Note that $\max \left\{\mathrm{x}_{o}{ }^{*}, \mathrm{x}_{l}{ }^{*}\right\}$ is the leftmost point that is to be found in both intervals:

a) if $\mathrm{x}_{a}{ }^{*}<\max \left\{\mathrm{x}_{o}{ }^{*}, \mathrm{x}_{l}{ }^{*}\right\}, \mathrm{P}_{p}\left(\mathrm{x}_{a}{ }^{*}\right) \cap \mathrm{R}^{v}\left(\mathrm{x}_{a}{ }^{*}\right)$ or $\mathrm{P}_{p}\left(\mathrm{x}_{a}{ }^{*}\right) \cap \mathrm{P}_{o}\left(\mathrm{x}_{a}{ }^{*}\right)$ is not empty, and the agent has to select $\mathrm{x}=\max \left\{\mathrm{x}_{o}{ }^{*}, \mathrm{x}_{l}{ }^{*}\right\}$. A policy closer to its ideal point will lead to legislative initiative: assume $\mathrm{x}<\max \left\{\mathrm{x}_{o}{ }^{*}, \mathrm{x}_{l}{ }^{*}\right\}$, so $\max \{o(\mathrm{x}), l(\mathrm{x})\}>\max \left\{\mathrm{x}_{o}{ }^{*}, \mathrm{x}_{l}{ }^{*}\right\}$. Then the legislator will set a final bill $\mathrm{y}<\max \{o(\mathrm{x}), l(\mathrm{x})\}$ and $\mathrm{y} \geq \max \left\{\mathrm{x}_{o}{ }^{*}\right.$, $\left.\mathrm{x}_{l}{ }^{*}\right\}$, which will be preferred by either the leftmost veto player or the override player. In any case, this bill, which is veto proof, will be accepted in a legislative process. Since $\mathrm{x}_{a}{ }^{*}<\max \left\{\mathrm{x}_{o}{ }^{*}, \mathrm{x}_{l}{ }^{*}\right\}$, the agent prefers an outcome $\mathrm{x}=\max \left\{\mathrm{x}_{o}{ }^{*}, \mathrm{x}_{l}{ }^{*}\right\}$ to a statutory policy $\mathrm{y} \geq$ $\max \left\{\mathrm{x}_{o}{ }^{*}, \mathrm{x}_{l}{ }^{*}\right\}$.

b) if $\max \left\{\mathrm{x}_{o}{ }^{*}, \mathrm{x}_{l}{ }^{*}\right\} \leq \mathrm{x}_{a}{ }^{*} \leq \mathrm{x}_{p}{ }^{*}$, then $\mathrm{P}_{p}\left(\mathrm{x}_{a}{ }^{*}\right) \cap \mathrm{R}^{v}\left(\mathrm{x}_{a}{ }^{*}\right)=\emptyset$ and $\mathrm{P}_{p}\left(\mathrm{x}_{a}{ }^{*}\right)$ $\cap \mathrm{P}_{o}\left(\mathrm{x}_{a}{ }^{*}\right)=\emptyset$, so the agent selects $\mathrm{x}=\mathrm{x}_{a}{ }^{*}$.

c) if $\mathrm{x}_{a}{ }^{*}>\mathrm{x}_{p}{ }^{*}$, the agent is induced to propose $\mathrm{x}=\mathrm{x}_{p}{ }^{*}$. Any policy $\mathrm{x}>$ $\mathrm{x}_{p}{ }^{*}$, will lead to legislative initiative and a new bill $\mathrm{y}=\mathrm{x}_{p}{ }^{*}$ that will not be vetoed, since $\mathrm{x}_{o}{ }^{*} \leq \mathrm{x}_{p}{ }^{*}$.

2. if $\mathrm{x}_{p}{ }^{*}=\mathrm{x}_{l}{ }^{*}$, the intervals $\left[\mathrm{x}_{l}{ }^{*}, \mathrm{x}_{r}{ }^{*}\right]$ and $\left[\mathrm{x}_{o}{ }^{*}, \mathrm{x}_{p}{ }^{*}\right]$ have only one point in common, that is, $\mathrm{x}_{p}{ }^{*}$. The agent is induced to select $\mathrm{x}=\mathrm{x}_{p}{ }^{*}$. Any deviation from this policy will lead to legislative initiative: assume that $\mathrm{x}<\mathrm{x}_{p}{ }^{*}$. Then, the legislator will introduce a bill $\mathrm{y}=\mathrm{x}_{p}{ }^{*}$, which will be veto proof since $\mathrm{x}_{i}{ }^{*}>\mathrm{x}_{p}{ }^{*}$ for all $i \in \mathrm{V}$.

Proof of Proposition 2-2 (override game, special majority): This proposition is based on the results of Proposition 1 and Proposition 2-1, and distinguishes two cases:

1. $\mathrm{x}_{a}{ }^{*}<\mathrm{x}_{o_{l}}{ }^{*}$ (united legislature): since a special majority can be formed, Proposition 2-1 can be applied. Define $\mathrm{x}_{o}{ }^{*} \equiv \mathrm{x}_{o_{l}}{ }^{*}$. By definition, $\mathrm{x}_{p}{ }^{*} \geq$ $\mathrm{x}_{o_{l}}{ }^{*}$. Given $\mathrm{x}_{a}{ }^{*}<\mathrm{x}_{o_{l}}{ }^{*}$, the agent selects $\max \left\{\mathrm{x}_{o_{l}}{ }^{*}, \mathrm{x}_{l}{ }^{*}\right\}$. Similarly, if $\mathrm{x}_{a}{ }^{*}>\mathrm{x}_{o_{r}}{ }^{*}$, it selects $\mathrm{x}=\min \left\{\mathrm{x}_{o_{l}}{ }^{*}, \mathrm{x}_{r}{ }^{*}\right\}$.

2. $\mathrm{x}_{o_{l}}{ }^{*} \leq \mathrm{x}_{a}{ }^{*} \leq \mathrm{x}_{o_{l}}{ }^{*}$ (divided legislature): since a veto cannot be overridden, the game can be characterized as a veto game. So Proposition 1 can be applied. For simplicity, assume $\mathrm{x}_{a}{ }^{*} \leq \mathrm{x}_{p}{ }^{*}$ : 
a) if $\mathrm{x}_{o_{l}}{ }^{*}>\mathrm{x}_{l}{ }^{*}$, the agent selects $\mathrm{x}=\mathrm{x}_{a}{ }^{*}$, since $\mathrm{x}_{a}{ }^{*}>\mathrm{x}_{l}{ }^{*}$.

b) if $\mathrm{x}_{o_{l}}{ }^{*} \leq \mathrm{x}_{l}{ }^{*}$ and $\mathrm{x}_{a}{ }^{*} \geq \mathrm{x}_{l}{ }^{*}$, the agent again selects $\mathrm{x}=\mathrm{x}_{a}{ }^{*}$. If $\mathrm{x}_{a}{ }^{*}<$ $\mathrm{x}_{l}{ }^{*}$, the agent has to choose $\mathrm{x}=\mathrm{x}_{l}{ }^{*}$ to avoid legislative action and $\mathrm{a}$ less preferred outcome.

A similar argument applies to $x_{a}{ }^{*} \geq x_{p}{ }^{*}$. Note that if the agent prefers to select a policy to the left of $\mathrm{x}_{o_{l}}{ }^{*}$ (or to the right of $\mathrm{x}_{o_{r}}{ }^{*}$ ), the result for the case of a united legislature applies, and the agent has to select $\mathrm{x}=$ $\max \left\{\mathrm{x}_{o_{l}}{ }^{*}, \mathrm{x}_{l}{ }^{*}\right\}$ (or $\min \left\{\mathrm{x}_{o_{r}}{ }^{*}, \mathrm{x}_{r}{ }^{*}\right\}$ ).

Proof of Proposition 3 (gatekeeping game): In the last stage, the legislator will select $\mathrm{y}=\mathrm{x}_{p}{ }^{*}$. Define $\mathrm{R}^{g}=\bigcap_{i} \mathrm{R}_{i}(\mathrm{y})$ for all gatekeepers $i \in \mathrm{G}, \mathrm{G}=\left\{g_{1}, \ldots g_{g}\right\} \subset$ M. Also define $\mathrm{x}_{g_{\max }}{ }^{*}=\max \left\{\mathrm{x}_{i}{ }^{*}\right\}$ and $\mathrm{x}_{g_{\min }}{ }^{*}=\min \left\{\mathrm{x}_{i}{ }^{*}\right\}$ for these players. Knowing the legislator's response, the gatekeepers in the game will accept the agent proposal if $\mathrm{x} \in \mathrm{R}^{g}$. Two cases need to be distinguished:

1. if $\mathrm{x}_{g_{\min }}{ }^{*} \leq \mathrm{x}_{p}{ }^{*} \leq \mathrm{x}_{g_{\max }}{ }^{*}$ (opposing gatekeepers), then $\mathrm{R}^{g}=\left\{\mathrm{x}_{p}{ }^{*}\right\}$. So the agent has to select $\mathrm{x}=\mathrm{x}_{p}{ }^{*}$, otherwise legislation will be initiated which leads to a lower payoff for the agent.

2. if $\mathrm{x}_{p}{ }^{*}>\mathrm{x}_{g_{\max }}{ }^{*}$ (gatekeepers with common interest), then $\mathrm{R}^{g}=\mathrm{R}_{g_{\max }}\left(\mathrm{x}_{p}{ }^{*}\right)$. The decisive gatekeeper, $g_{\max }$, will not initiate legislation if $\mathrm{x} \in \mathrm{R}_{g_{\max }}\left(\mathrm{x}_{p}{ }^{*}\right)$. To avoid legislation the agent has to select the following policy from this set:

a) if $\mathrm{x}_{a}{ }^{*}<\mathrm{g}_{\max }\left(\mathrm{x}_{p}{ }^{*}\right), \mathrm{x}=g_{\max }\left(\mathrm{x}_{p}{ }^{*}\right)$. Policies closer to $\mathrm{x}_{a}{ }^{*}$ will trigger legislation: assume $\mathrm{x}<\mathrm{g}_{\max }\left(\mathrm{x}_{p}{ }^{*}\right)$, then $\mathrm{U}_{g_{\max }}(\mathrm{x})<\mathrm{U}_{g_{\max }}(\mathrm{y})$, and the gatekeeper, $g_{\max }$, initiates legislation leading to a final bill $\mathrm{x}_{p}{ }^{*}$, which the agent prefers less.

b) if $g_{\max }\left(\mathrm{x}_{p}{ }^{*}\right) \leq \mathrm{x}_{a}{ }^{*} \leq \mathrm{x}_{p}{ }^{*}, \mathrm{x}=\mathrm{x}_{a}{ }^{*}$.

c) if $\mathrm{x}_{a}{ }^{*}>\mathrm{x}_{p}{ }^{*}, \mathrm{x}=\mathrm{x}_{p}{ }^{*}$. If $a$ proposes $\mathrm{x}>\mathrm{x}_{p}{ }^{*}$, the gatekeeper releases a bill leading to $\mathrm{y}=\mathrm{x}_{p}{ }^{*}$. This yields a lower payoff to the agent.

A similar argument applies to $\mathrm{x}_{p}{ }^{*}<\mathrm{x}_{g_{\min }}{ }^{*}$.

Proof of Proposition 4 (gatekeeping-veto game): Note that, as in a veto game, the legislator will select its best veto proof bill from $\mathrm{R}^{v} \cap \mathrm{P}_{p}(\mathrm{x})$. With regard to the response of the gatekeeper, two cases have to be distinguished:

1. if $\mathrm{x}_{l}{ }^{*} \leq \mathrm{x}_{g}{ }^{*} \leq \mathrm{x}_{r}{ }^{*}$,

a) and if $\mathrm{x}_{l}{ }^{*} \leq \mathrm{x}_{a}{ }^{*} \leq \mathrm{x}_{r}{ }^{*}$, Proposition 1 applies: the agent selects $\mathrm{x}=$ $\mathrm{x}_{a}^{*}$, 
b) and if $\mathrm{x}_{a}{ }^{*}<\mathrm{x}_{l}{ }^{*}$, the agent proposes $\mathrm{x}=\mathrm{x}_{l}{ }^{*}$. A policy closer to $\mathrm{x}_{a}{ }^{*}$ will lead to a less preferred outcome: assume that $\mathrm{x}<\mathrm{x}_{l}{ }^{*}$. The legislator will propose a bill $\mathrm{y} \geq \mathrm{x}_{l}{ }^{*}$ and $\mathrm{y} \leq l(\mathrm{x})$. Since $\mathrm{x}_{g}{ }^{*} \geq \mathrm{x}_{l}{ }^{*}$, the gatekeeper prefers $\mathrm{y}$ to $\mathrm{x}$. Legislation will be initiated, which makes the agent worse off since it prefers $\mathrm{x}=\mathrm{x}_{p}{ }^{*}$ to a bill $\mathrm{y} \geq \mathrm{x}_{p}{ }^{*}$. A similar argument applies to $\mathrm{x}_{a}{ }^{*}>\mathrm{x}_{r}{ }^{*}$.

2. if $\mathrm{x}_{g}{ }^{*}<\mathrm{x}_{l}{ }^{*}$.

a) and if $\mathrm{x}_{l}{ }^{*} \leq \mathrm{x}_{a}{ }^{*} \leq \mathrm{x}_{r}{ }^{*}$, Proposition 1 applies: the agent selects $\mathrm{x}=$ $\mathrm{x}_{a}^{*}$.

b) if $\mathrm{x}_{a}{ }^{*}<\mathrm{x}_{l}{ }^{*}$, the gatekeeper, $g$, will not initiate legislation if $\mathrm{x} \in$ $\mathrm{R}_{g}(\mathrm{y})$.

i) if $\mathrm{x}_{l}{ }^{*} \neq \mathrm{x}_{p}{ }^{*}$, veto player $l$ has the most restrictive preference set. If $\mathrm{x}_{p}{ }^{*}<l(\mathrm{x})$, the legislator will select $\mathrm{y}=\mathrm{x}_{p}{ }^{*}$. Given $\mathrm{R}_{g}\left(\mathrm{x}_{p}{ }^{*}\right)$, the agent chooses $\mathrm{x}=g\left(\mathrm{x}_{p}{ }^{*}\right)$ if $\mathrm{x}_{a}{ }^{*} \leq g\left(\mathrm{x}_{p}{ }^{*}\right)$, or $\mathrm{x}=\mathrm{x}_{a}{ }^{*}$ if $\mathrm{x}_{a}{ }^{*}>$ $g\left(\mathrm{x}_{p}{ }^{*}\right)$ (see Proposition 3 for a single gatekeeper).

A special case occurs when $\mathrm{x}_{p}{ }^{*} \geq l(\mathrm{x})$. The legislator will select a veto proof bill $\mathrm{y}=l(\mathrm{x})$. Since $\mathrm{x}_{g}{ }^{*}<\mathrm{x}_{l}{ }^{*}, g(l(\mathrm{x}))<\mathrm{x}$, and $\mathrm{x} \in$ $\mathrm{R}_{g}(l(\mathrm{x}))$. The gatekeeper will not initiate legislation since $\mathrm{x}$ will always be in its preference set. The agent selects $\mathrm{x}=\mathrm{x}_{a}{ }^{*}$. Note that $g(l(\mathrm{x}))>g\left(\mathrm{x}_{p}{ }^{*}\right)$ since $l(\mathrm{x})<\mathrm{x}_{p}{ }^{*}$.

ii) if $\mathrm{x}_{l}{ }^{*}=\mathrm{x}_{p}{ }^{*}$, the legislator proposes $\mathrm{y}=\mathrm{x}_{p}{ }^{*}$, since $v_{i}(\mathrm{x})>\mathrm{x}_{v_{i}}{ }^{*}>$ $\mathrm{x}_{p}{ }^{*}$. Given $\mathrm{R}_{g}\left(\mathrm{x}_{p}{ }^{*}\right)$, the agent selects $\mathrm{x}=g\left(\mathrm{x}_{p}{ }^{*}\right)$ if $\mathrm{x}_{a}{ }^{*} \leq g\left(\mathrm{x}_{p}{ }^{*}\right)$, or $\mathrm{x}=\mathrm{x}_{a}{ }^{*}$ if $\mathrm{x}_{a}{ }^{*}>g\left(\mathrm{x}_{p}{ }^{*}\right)$ (and $\mathrm{x}_{a}{ }^{*}<\mathrm{x}_{l}{ }^{*}$ ) (Proposition 3 for a single gatekeeper).

Note that a similar argument applies to $\mathrm{x}_{g}{ }^{*}>\mathrm{x}_{r}{ }^{*}$.

Proof of Proposition 5-1 (gatekeeping-override game, unique player): Note that, as in an override game with a unique player, the legislator selects its best bill from $\mathrm{P}_{p}(\mathrm{x}) \cap\left(\mathrm{R}^{v} \cup \mathrm{P}_{o}(\mathrm{x})\right)$. The gatekeeper now has to decide whether or not it prefers this bill to the agent policy. Assuming $\mathrm{x}_{p}{ }^{*} \geq \mathrm{x}_{o}{ }^{*}$, the following cases need to be distinguished:

1. if $\max \left\{\mathrm{x}_{o}{ }^{*}, \mathrm{x}_{l}{ }^{*}\right) \leq \mathrm{x}_{g}{ }^{*} \leq \mathrm{x}_{p}{ }^{*}$,

a) and if $x_{a}{ }^{*}<\max \left\{x_{o}{ }^{*}, x_{l}{ }^{*}\right\}$, the agent proposes $x=\max \left\{x_{o}{ }^{*}, x_{l}{ }^{*}\right\}$. If it propose a policy closer to $x_{a}{ }^{*}$, the gatekeeper will initiate legislation.

b) and if $\max \left\{\mathrm{x}_{o}{ }^{*}, \mathrm{x}_{l}{ }^{*}\right\} \leq \mathrm{x}_{a}{ }^{*} \leq \mathrm{x}_{p}{ }^{*}$, the agent selects $\mathrm{x}=\mathrm{x}_{a}{ }^{*}$ (see Proposition 2-1).

c) and if $\mathrm{x}_{a}{ }^{*}>\mathrm{x}_{p}{ }^{*}$, the agent selects $\mathrm{x}=\mathrm{x}_{p}{ }^{*}$ (see Proposition 2-1). Note that $\mathrm{x}_{g}{ }^{*} \leq \mathrm{x}_{p}{ }^{*}$, so the gatekeeper prefers the bill $\mathrm{y}=\mathrm{x}_{p}{ }^{*}$ to a proposal $\mathrm{x}>\mathrm{x}_{p}{ }^{*}$.

2. if $\mathbf{x}_{g}^{*}<\max \left\{\mathbf{x}_{o}^{*}, \mathbf{x}_{l}^{*}\right\}$, 
a) if $\mathrm{x}_{a}{ }^{*}<\max \left\{\mathrm{x}_{o}{ }^{*}, \mathrm{x}_{l}{ }^{*}\right\}$, the gatekeeper will not initiate legislation if $\mathrm{x} \in \mathrm{R}_{g}(\mathrm{y})$. Two subcases need to be distinguished:

i) if $\mathrm{x}_{l}{ }^{*} \neq \mathrm{x}_{p}{ }^{*}$, the leftmost veto player or the override player has the most restrictive preference set. If $\mathrm{x}_{p}{ }^{*}<\max \{o(\mathrm{x}), l(\mathrm{x})\}$, the legislator will select $\mathrm{y}=\mathrm{x}_{p}{ }^{*}$. Given $\mathrm{R}_{g}\left(\mathrm{x}_{p}{ }^{*}\right)$, the agent chooses $\mathrm{x}=$ $g\left(\mathrm{x}_{p}{ }^{*}\right)$ if $\mathrm{x}_{a}{ }^{*} \leq g\left(\mathrm{x}_{p}{ }^{*}\right)$, or $\mathrm{x}=\mathrm{x}_{a}{ }^{*}$ if $\mathrm{x}_{a}{ }^{*}>g\left(\mathrm{x}_{p}{ }^{*}\right)$ (Proposition 3 for a single gatekeeper). A special case occurs when $\mathrm{x}_{p}{ }^{*} \geq$ $\max \{o(\mathrm{x}), l(\mathrm{x})\}$. Define $o(\mathrm{x})^{-}$as the next proposal to the left of $o(\mathrm{x})$. Now the legislator will select a veto proof bill $\mathrm{y}=$ $\max \left\{o(\mathrm{x})^{-}, l(\mathrm{x})\right\}$. Since $\mathrm{x}_{g}{ }^{*}<\max \left\{\mathrm{x}_{o}{ }^{*}, \mathrm{x}_{l}{ }^{*}\right\}, g(\mathrm{y})<\mathrm{x}$ for $\mathrm{y}$ $=\max \left\{o(\mathrm{x})^{-}, l(\mathrm{x})\right\}$. The gatekeeper will not initiate legislation since $\mathrm{x}$ will always be in its preference set. The agent selects $\mathrm{x}$ $=\mathrm{x}_{a}{ }^{*}$. Note that $g(\mathrm{y})>g\left(\mathrm{x}_{p}{ }^{*}\right)$ for $\mathrm{y}=\max \left\{o(\mathrm{x})^{-}, l(\mathrm{x})\right\}$, since $\max \left\{o(\mathrm{x})^{-}, l(\mathrm{x})\right\}<\mathrm{x}_{p}{ }^{*}$.

ii) if $\mathrm{x}_{l}{ }^{*}=\mathrm{x}_{p}{ }^{*}$, the legislator proposes $\mathrm{y}=\mathrm{x}_{p}{ }^{*}$ (see Proposition 2-1). Given $\mathrm{R}_{g}\left(\mathrm{x}_{p}{ }^{*}\right)$, the agent selects $\mathrm{x}=g\left(\mathrm{x}_{p}{ }^{*}\right)$ if $\mathrm{x}_{a}{ }^{*} \leq g\left(\mathrm{x}_{p}{ }^{*}\right)$, or $\mathrm{x}=\mathrm{x}_{a}{ }^{*}$ if $\mathrm{x}_{a}{ }^{*}>g\left(\mathrm{x}_{p}{ }^{*}\right)$ (Proposition 3 for a single gatekeeper).

b) and if $\max \left\{\mathrm{x}_{a}{ }^{*}, \mathrm{x}_{l}{ }^{*}\right\} \leq \mathrm{x}_{a}{ }^{*} \leq \mathrm{x}_{p}{ }^{*}$, the agent selects $\mathrm{x}=\mathrm{x}_{a}{ }^{*}$ (see Proposition 2-1).

c) and if $\mathrm{x}_{a}{ }^{*}>\mathrm{x}_{p}{ }^{*}$, the agent selects $\mathrm{x}=\mathrm{x}_{p}{ }^{*}$ (see Proposition 2-1). Since $\mathrm{x}_{g}{ }^{*}<\max \left\{\mathrm{x}_{o}{ }^{*}, \mathrm{x}_{l}{ }^{*}\right\}$, the gatekeeper prefers a bill $\mathrm{y}=\mathrm{x}_{p}{ }^{*}$ to $\mathrm{a}$ proposal $\mathrm{x}>\mathrm{x}_{p}{ }^{*}$.

Proof of Proposition 5-2 (gatekeeping-override game, special majority): This proposition is based on the results of Propositions 2-2, 4 and 5-1, and distinguished two cases:

1. if $\mathrm{x}_{a}{ }^{*}<\mathrm{x}_{o_{l}}{ }^{*}$, a special majority can be formed to override a veto, so Proposition 5-1 can be applied. Define $\mathrm{x}_{o}{ }^{*} \equiv \mathrm{x}_{o_{l}}{ }^{*}$. Note that, by definition $\mathrm{x}_{p}{ }^{*} \geq \mathrm{x}_{o_{l}}{ }^{*}$.

a) if $\mathrm{x}_{g}{ }^{*}<\max \left\{\mathrm{x}_{o_{l}}{ }^{*}, \mathrm{x}_{l}{ }^{*}\right\}$, the agent selects $\mathrm{x}=g\left(\mathrm{x}_{p}{ }^{*}\right)$ if $\mathrm{x}_{a}{ }^{*}<g\left(\mathrm{x}_{p}{ }^{*}\right)$, or $\mathrm{x}=\mathrm{x}_{a}{ }^{*}$ if $\mathrm{x}_{a}{ }^{*} \geq g\left(\mathrm{x}_{p}{ }^{*}\right)$ (see Proposition 5-1). Similarly, if $\mathrm{x}_{a}{ }^{*}>$ $\mathrm{x}_{o_{r}}{ }^{*}$ and $\mathrm{x}_{g}{ }^{*}>\min \left\{\mathrm{x}_{o_{r}}{ }^{*}, \mathrm{x}_{r}{ }^{*}\right\}$, the agent selects $\mathrm{x}=g\left(\mathrm{x}_{p}{ }^{*}\right)$ if $\mathrm{x}_{a}{ }^{*}>$ $g\left(\mathrm{x}_{p}^{*}\right)$, or $\mathrm{x}=\mathrm{x}_{a}{ }^{*}$ if $\mathrm{x}_{a}{ }^{*} \leq g\left(\mathrm{x}_{p}{ }^{*}\right)$.

b) if $\max \left\{\mathrm{x}_{o_{l}}{ }^{*}, \mathrm{x}_{l}{ }^{*}\right\} \leq \mathrm{x}_{g}{ }^{*} \leq \mathrm{x}_{p}{ }^{*}$, and given $\mathrm{x}_{a}{ }^{*}<\mathrm{x}_{o_{l}}{ }^{*}$, the agent selects $\mathrm{x}=\max \left\{\mathrm{x}_{o_{l}}{ }^{*}, \mathrm{x}_{l}{ }^{*}\right\}$ (see Proposition 5-1). Similarly, if $\mathrm{x}_{a}{ }^{*}>\mathrm{x}_{o_{r}}{ }^{*}$ and $\mathrm{x}_{p}{ }^{*} \leq \mathrm{x}_{g}{ }^{*} \leq \min \left\{\mathrm{x}_{o_{r}}{ }^{*}, \mathrm{x}_{r}{ }^{*}\right\}$, it selects $\mathrm{x}=\min \left\{\mathrm{x}_{\boldsymbol{o}_{r}}{ }^{*}, \mathrm{x}_{r}{ }^{*}\right\}$.

2. if $\mathrm{x}_{o_{l}}{ }^{*} \leq \mathrm{x}_{a}{ }^{*} \leq \mathrm{x}_{o_{r}}{ }^{*}$, a veto cannot be overridden, so Proposition 4 can be applied.

a) if $\mathrm{x}_{l}{ }^{*} \leq \mathrm{x}_{g}{ }^{*} \leq \mathrm{x}_{r}{ }^{*}$ and: 
i) if $\mathrm{x}_{l}{ }^{*} \leq \mathrm{x}_{o_{l}}{ }^{*}$ and $\mathrm{x}_{a}{ }^{*} \leq \mathrm{x}_{p}{ }^{*}$, the agent selects $\mathrm{x}=\mathrm{x}_{a}{ }^{*}$, since $\mathrm{x}_{l}{ }^{*} \leq$ $\mathrm{x}_{a}{ }^{*}$. Similarly, if $\mathrm{x}_{r}{ }^{*} \geq \mathrm{x}_{o_{r}}{ }^{*}$ and $\mathrm{x}_{a}{ }^{*} \geq \mathrm{x}_{p}{ }^{*}$, the agent also selects $\mathrm{x}=\mathrm{x}_{a}{ }^{*}$. Note that if $\mathrm{x}_{a}{ }^{*}=\mathrm{x}_{o_{l}}{ }^{*}, \mathrm{x}=\mathrm{x}_{o_{l}}{ }^{*}$.

ii) if $\mathrm{x}_{l}{ }^{*}>\mathrm{x}_{o_{l}}{ }^{*}$ and $\mathrm{x}_{l}{ }^{*} \leq \mathrm{x}_{a}{ }^{*} \leq \mathrm{x}_{p}{ }^{*}$, the agent again selects $\mathrm{x}=$ $\mathrm{x}_{a}{ }^{*}$. If $\mathrm{x}_{a}{ }^{*}<\mathrm{x}_{l}{ }^{*}$, the agent has to choose $\mathrm{x}=\mathrm{x}_{l}{ }^{*}$. Similarly, if $\mathrm{x}_{r}{ }^{*}<\mathrm{x}_{o_{r}}{ }^{*}$ and $\mathrm{x}_{p}{ }^{*} \leq \mathrm{x}_{a}{ }^{*} \leq \mathrm{x}_{r}{ }^{*}$, the agent selects $\mathrm{x}=\mathrm{x}_{a}{ }^{*}$. If $\mathrm{x}_{a}{ }^{*}>\mathrm{x}_{r}{ }^{*}$, the agent has to choose $\mathrm{x}=\mathrm{x}_{r}{ }^{*}$.

b) if $\mathrm{x}_{g}{ }^{*}<\mathrm{x}_{l}{ }^{*}$ and:

i) if $\mathrm{x}_{o_{l}}{ }^{*} \geq \mathrm{x}_{l}{ }^{*}$ and $\mathrm{x}_{a}{ }^{*} \leq \mathrm{x}_{p}{ }^{*}$, the agent selects $\mathrm{x}=\mathrm{x}_{a}{ }^{*}$, since $\mathrm{x}_{a}{ }^{*} \geq$ $\mathrm{x}_{l}{ }^{*}$ (Proposition 4). If $\mathrm{x}_{a}{ }^{*} \geq \mathrm{x}_{p}{ }^{*}$, the gatekeeper does not block legislation, since $\mathrm{x}_{g}{ }^{*}<\mathrm{x}_{p}{ }^{*}$. The agent selects $\mathrm{x}=\mathrm{x}_{a}{ }^{*}$ if $\mathrm{x} \leq$ $\min \left\{\mathrm{x}_{o_{r}}{ }^{*}, \mathrm{x}_{r}{ }^{*}\right\}$, or $\mathrm{x}=\min \left\{\mathrm{x}_{o_{r}}{ }^{*}, \mathrm{x}_{r}{ }^{*}\right\}$ if $\mathrm{x}_{a}{ }^{*}>\min \left\{\mathrm{x}_{o_{r}}{ }^{*}, \mathrm{x}_{r}{ }^{*}\right\}$ (see Proposition 2-2).

ii) if $\mathrm{x}_{o_{l}}{ }^{*}<\mathrm{x}_{l}{ }^{*}$ and $g\left(\mathrm{x}_{p}{ }^{*}\right) \leq \mathrm{x}_{a}{ }^{*} \leq \mathrm{x}_{p}{ }^{*}$, the agent selects $\mathrm{x}=\mathrm{x}_{a}{ }^{*}$. If $\mathrm{x}_{a}{ }^{*}<g\left(\mathrm{x}_{p}{ }^{*}\right)$ (and $\left.\mathrm{x}_{a}{ }^{*} \geq \mathrm{x}_{o_{l}}{ }^{*}\right)$, it has to select $\mathrm{x}=g\left(\mathrm{x}_{p}{ }^{*}\right)$. If $\mathrm{x}_{a}{ }^{*} \geq \mathrm{x}_{p}{ }^{*}$, the agent again selects $\mathrm{x}=\mathrm{x}_{a}{ }^{*}$ if $\mathrm{x} \leq \min \left\{\mathrm{x}_{o_{r}}{ }^{*}, \mathrm{x}_{r}{ }^{*}\right\}$, or $\mathrm{x}=\min \left\{\mathrm{x}_{o_{r}}{ }^{*}, \mathrm{x}_{r}{ }^{*}\right\}$ if $\mathrm{x}_{a}{ }^{*}>\min \left\{\mathrm{x}_{o_{r}}{ }^{*}, \mathrm{x}_{r}{ }^{*}\right\}$.

A similar argument applies to $\mathrm{x}_{g}{ }^{*}>\mathrm{x}_{r}{ }^{*}$. 